\title{
A Prioritization Model of Strategies for Small and Medium Firms in Less-Developed Countries: A Tanzania Case
}

\author{
Kunhui Ye and Ramadhani Said Tekka \\ School of Management Science and Real Estate, Chongqing University, 83\# Shabei Street, Shapingba District, Chongqing 400045, \\ China \\ Correspondence should be addressed to Ramadhani Said Tekka; ramsotekka@yahoo.co.uk
}

Received 4 March 2020; Revised 15 July 2020; Accepted 28 July 2020; Published 14 August 2020

Academic Editor: Dong Zhao

Copyright (c) 2020 Kunhui Ye and Ramadhani Said Tekka. This is an open access article distributed under the Creative Commons Attribution License, which permits unrestricted use, distribution, and reproduction in any medium, provided the original work is properly cited.

\begin{abstract}
Most construction industries (CIs) from less-developed countries (LDC) have been overwhelmed with many construction project's challenges. The challenges have always been leading to prolonged unimproved performance of small and medium firms (SMFs). This study aimed to develop a prioritization model of strategies for performance improvement of SMF. Business process re-engineering (BPR) is adopted to facilitate the identification of the re-engineering core process as value activities and develop a conceptual framework for the study. The study used the questionnaire and interview survey to collect data from 253 respondents sampled through purposive sampling. Respondents were obtained from twenty-eight firms obtained through a systematic approach that helped to get firms practicing BPR. Data were analyzed using SPSS 24-AMOS to create structural equation modelling. Findings have revealed twelve (12) weakness indicators, seven (7) performance measure indicators, eleven (11) construction core process strategies, and sixteen (16) organizational strategies. Strategies were clustered into the seven-cluster matrix, namely: resources, capacity building, operational, government policy, design, procurement, and construction management, having a positively significant correlation on SMF's performance improvement. The study findings revealed that the BPR technique has globally become a useful tool for many organizations seeking to attain an improved performance since it provides a chance to re-engineer the organization process. Thus, for the firm(s) to enhance performance improvement, it is recommended for LDC's construction firm(s) to adopt re-engineering process management techniques to identify and prioritize the construction core process and organizational strategies to attain improved performance.
\end{abstract}

\section{Introduction}

The current era we live in differs expressively from that of past decades. Nowadays, different firms are struggling to respond to the increasing demands of clients' needs. The need has brought to an intensive global competition of which domestic firms in less-developed countries (LDCs) can no longer escape from it. In the local competitive environment, competitors attempt to identify and improve competitive market features aiming to perform better in terms of lower cost and quality, and within reasonable delivery time [1]. Thus, to tolerate within a global competition, creativity and innovation for efficient performance have been compulsory in scanning business to eliminate unnecessarily and remain with only essential performance process (s), which contribute to attaining the final goals. In a current volatile, dynamic, and a competitive environment where the conglomerate firms are struggling in the same domestic market with small and medium contractors (SMCs), the basis of firms to achieve better performance has remained into attributes including resources, experts, and organizational or firm's value-adding-strategic processes.

Over the past decades, SMC in LDC has been documented to play a fundamental role in economic growth through constructed infrastructure facilities. The facilities have provided physical shelter, offered employment, and generated income that has accelerated productivity and quality standard life and acts as a basis for social-economic development [2]. Despite its social-economic contributions, SMC has continuously confronted with numerous 
challenges, such as lack of appropriate and continuous strategies for firm development. The effects of the obstacles have enhanced the fallen short of expected performance in terms of the project's contract time overrun, safety, overbudget, and poor quality [3]. Various studies have formulated several strategies to improve the performance of SMC. These include the formulation of different agencies, formulation of programs, and policy [4]. However, it has been pointed out that the formulated strategies have tended to be imprecise, changeable, doubtful, and at times incompatible. One of the main reasons is that they do not directly focus on specific process(s) intended for change, instead focusing on addressing and fixing the problem more quickly without understanding the root cause [5].

Most firms in LDC are still being faced with a commission of mapping and developing a new strategy and a holistic process approach to guarantee the SMC construction performance improvement [6]. Tekka and Ye [7] proposed the prioritization of the potential strategies that integrate SMC's resources and process(s) as among the best approaches to attain improved performance. A study by Muhegi [8] supported that a comprehensive strategy will help contractors to understand the difficulties of establishing a substantial performance gap. Furthermore, Christopher et al. [9] emphasized that prioritization of strategy is crucial to be fitted and aligned with management processes, resources such as competent and skilled labor, finance, and equipment. Towards alignment, adoption of business process re-engineering (BPR) as a driver to enhance a drastic change of a firm's performance in terms of effectiveness, efficiency, productivity, profitability, and quality cannot be ignored. Thus, this study takes a primary step to adopt the BPR philosophy to prioritize strategies for SMC's performance improvement. The findings lay a foundation for SMC policymakers and stakeholders on strategy prioritization to attain an improved performance as a competitive advantage.

\section{Literature Review}

2.1. Concepts of Small and Medium Enterprises (SMEs). Small and medium enterprises (SMEs) are sometimes recognized by various international organizations such as the World Bank (WB), European Union (EU), United Nations (UN), and World Trade Organization (WTO) as micro, small, and medium enterprises having a fundamental contribution to the economy of any country. Despite its recognition, the literature review has acknowledged the absence of a standard definition of small and medium enterprises (SMEs). The often-referred definition was grounded on commonly and most used criteria such as annual turnover, number of employees, and the amount of investment [10]. Due to differences in economies from one region to the other which affect the value of the invested capital, the annual volume of turnover, and the number of employees, the definition of SME based on these variables also varies from one region to the other as defined by multilateral institutions (Table 1).

Moreover, the Organization for Economic Co-operation and Development (OECD) recognized that the definition of
SME depends mainly on the country legislature, which considers the economy of a particular country in stating the dimension of "small and medium." In the same vein, the Asian Development Bank Institute coined that, under developing countries' perspective, the definition of SME could vary by country, by firm size as well as by statistical definition. Furthermore, in developing countries, the definition extends from general to specialty depending on specialization, local, regional, international, or multinational depending on the operational scope as well as permanent to temporary. In most sub-Saharan and southern African countries, including Tanzania, the classification varies from class one that ranges from medium-large to class six or seven, the smallest. When defining small and medium contractors (SMCs) as enterprises under construction industry viewpoint, the categorization of SMC is determined based on the contract category under the bid tendered which involves financial capacity and technical capability of the contractor to execute a particular task (the size of the projector or contract) [11]. In developed and industrialized countries, the classification mostly remains onto smallmedium-to-large enterprises. However, its definition extends based on the evaluation of the resource, ownership, partnership, and linkages.

Tanzania is historically recognized to adopt the socialism and self-reliance strategy path immediately after its independence in 1961 intended for its national development. The policy was set to follow the way for the direct state capture, and the governor of all means of production resulted in the nationalization of all key private previously owned businesses ventures by government parastatals [12]. This strategy acknowledged the social-economic development in terms of water delivery, education, and health services. Consequently, the path attained a negative effect leading to poor economic results in terms of economic crises and imbalances for some decades. The emerged economic crisis marked the need for a transitional policy change from administratively statecontrolled economy towards a free-market economy. Thus, to ascertain the economic reforms, various government-led initiatives were taken including review of tax structure, trade liberalization, and reforms of the public sector which lead to a shift from a public-sector driven economy to market liberalization. The economic transformation encouraged and promoted the private sector (small and medium enterprises) establishment, which has become the engine for the country economy and the great source of employment.

In Tanzania, the acronym SMEs describes the small-, micro-, and medium-scale enterprises. It is seldom used synonymously with micro, small, and medium enterprises. The Tanzania government describes SME with respect to the sector, the capital invested, and the number of employees. Subsequently, SMEs are defined as micro-, small-, and medium-sized enterprises in nonfarm activities, including manufacturing, mining, commerce, and services. A small microenterprise comprises 5 to 49 employees exemplified to include small shops in the cities; a medium enterprise occupies 50 to 99 employees consisting of a manufacturing firm and an exporting company. Furthermore, a large enterprise has equal to or more than 100 employees. However, 
TABLE 1: SME definitions used by multilateral institutions.

\begin{tabular}{lccccc}
\hline \multirow{2}{*}{ Institution } & \multicolumn{3}{c}{ Number of employees } & \multicolumn{2}{c}{ Turnover (euro) } \\
& Micro & Small & Medium & Micro & Small \\
\hline World Bank & $1-9$ & $<50$ & $50-249$ & & Maximum 15,000,000 \\
Asian Development Bank & & No official definition, apply, only definitions of individual national governments. & Nil Nil & & $<$ million \\
African Development Bank & $1-9$ & $\leq 50$ & Nil & $<€ 50$ million \\
EU & Nil & $<50$ & $50-249$ & $<€ 2$ million & $<€ 10$ Nil \\
SADC \& ECOWAS & $0-9$ & $10-49$ & $50-249$ & & $\leq € 10$ million \\
Developed countries & $0-9$ & $10-49$ & $50-249$ & $\leq € 2$ million & $\leq € 43$ million \\
\hline
\end{tabular}

Note: 1euro $=1822.32$ USD, 2008; source: the authors have extracted from BED.

capital investment ranges from less than 5 Tshs million (2160.17USD) to over 100 Tshs million (43,230.37USD). Tanzania has an inaugurated SME policy aiming for capacity building to exploit various opportunities of a vibrant SME sector. Multiple agencies and institutions such as Small Industries Development Organization (SIDO), Tanzania Trade Development Authority (TAN-TRADE), Weights and Measures Agency (WMA), Tanzania Bureau of Standards (TBS), and Tanzania Private Sector Foundation (TPSF) to mention a few have been established to support SME advancement [13]. However, in collaboration with development partners such as the United Nations Development Programme (UNDP), the World Bank (WB), and the International Labor Organization (ILO), Tanzania has provided various training related to market demands, entrepreneurship, quality control, and the like.

In Tanzania, construction industry contextual, the small and medium contractors are classified based on the limits of the work as contract value to be tendered (Table 2) or financial capacity and technical capability of the contractor to execute a particular task. Furthermore, this describes the economics, including financial, equipment, and personnel resources possessed by the firm.

SME is acknowledged globally to play a significant role in enhancing sustainable industrialization. It promotes income distribution and poverty reduction, supports large-scale enterprises, and provides a broader ecosystem of enterprises for social-economic stability and well-being [14]. It is believed to contribute to about $90 \%$ of the total world business, more than $45 \%$ employment and 33\% GDP contribution to developing countries and 70\% employment in industrialized countries. SME as enterprises entails various attributes substantial in making the decision that influences productivity and stimulates and sustains growth. Profoundly, many SMEs in LDCs depend on the owner's skills, ability, and capability as well as personal attributes (characteristics) who perform many operational and management tasks for the prosperity of the business. SMC as SME registered by relevant bodies is owned as sole proprietors and partners who struggle to raise their financial capital from their savings. Although access to credit is a fundamental determinant of firm performance, SMCs are seriously attributed to lack of finance for investment [15] since most financial institutes consider SMC as high-risk borrowers and hence impose high-interest charge rate as a commission on risky loan. Similarly, most SMCs employ cheap, unskilled, and incompetent labor who have no financial and management skills. Thus, it led to inaccurate, doubtful, and lack of financial and accounting records. Correspondingly, SMCs are attributed to short- and medium-term strategies of survival rather than a long term that focuses on profitability and market share. They own the least sophisticated technology and slower to capture advantage of the latest affordable technology to ensure their competitiveness.

In many developing economies, many SMCs are characterized to operate within an inadequate infrastructure facility environment, which affects performances. Most rural and regional areas have insufficient infrastructure facilities, which hinder SMC growth. Firms have to bear an extra cost to obtain such an infrastructure service, which tends to reduce the profit of the firm. It can generally be summarized that SMC shares many common attributes. However, Sexton and Barrett [16] revealed that four fundamental and unique characteristics, including financial resources, management skill and knowhow, information as resources, and technical employee, could be used to differentiate performance from one firm to the other. Therefore, in a local competitive market where foreign firms have attained adequate attributes and performance, local SMC will continue to strive against foreign firm competitors due to weak and ineffective characteristics as well as inadequate performance. Thus, this study aims to prioritize the strategies to create a competitive advantage to local SMC.

Most Tanzanians make their living in small- and medium-scale agriculture enterprise activities which have occupied a pivotal position and estimated to contribute $27 \%$ to the GDP and $23.4 \%$ of the total labor force [17]. However, the agriculture sector has occupied a limited transformation conquered by subsistence farming within small average plot sizes and limited mechanization. It is through SMEs that agricultural economic transformation depends on modernization production that will increase agricultural productivity. It was reported that Tanzania comprises approximately 3 million enterprises with (98\%) microenterprises characterized to employ less than five employees affiliated into various businesses such as manufacturing, retail and trade, agricultural, and other services.

SME as a basis for private sector growth has been acknowledged to play a fundamental role in developing and growth of Tanzania national economy through the creation of employment and helps individuals to mobilize and find avenues for investment and generate income, providing equally income distribution that has significantly contributed to alleviate poverty. Similarly, the SMC in Tanzania has 
TABle 2: Classification of contractor enterprises in Tanzania.

\begin{tabular}{|c|c|c|c|c|c|}
\hline \multirow{2}{*}{ Class of registration } & \multicolumn{5}{|c|}{ Class limit for single contract (million TZS) } \\
\hline & Civil & Building & Electrical & Mechanical & Specialist firm \\
\hline One & Unlimited & Unlimited & Unlimited & Unlimited & Unlimited \\
\hline Two & 8000 & 5000 & 3000 & 3000 & 800 \\
\hline Three & 4000 & 3000 & 1500 & 1500 & 300 \\
\hline Four & 2000 & 1800 & 900 & 900 & \\
\hline Five & 1100 & 900 & 450 & 450 & \\
\hline Six & 500 & 400 & 250 & 250 & \\
\hline Seven & 200 & 200 & 150 & 150 & \\
\hline
\end{tabular}

Note: 1 USD = 2200 Tshs; sources: CRB, 2020.

played an essential social-economical role. They directly influence and stimulate the everyday lives of most citizens. They provide the physical infrastructures, which encompass constructed commercial and residential building, and communication networks involving roads, airport, and Standard Gauge Railway (SGR), to mention a few which have contributed a high economic growth averaging $6-7 \%$ annually in the past decade.

Tanzania is characterized by having large informal and underperforming SMEs with leading low economic value trading commodities including fish, tea, cotton, salt, and maize textile products with very little export commodities left to neighbor countries. However, selling low-value product has made Tanzania continue being less competitive that leads to a low capacity for economic growth [18]. Also, Tanzanian SMEs are faced with a critical challenge of formalization. A report by the National Baseline Survey indicated that most (96.1\%) SMEs in Tanzania lack formal registration which has made SMEs fail in accessing the loan for their growth [19] and hence fail to grow because of the high cost of raw materials, intensive competition, high tax rates, and corruption. Besides, lack of technology services has made them fail in finding new business opportunity and models, fail to raise the awareness, fail to transfer knowledge and technology, stimulating creativity and entrepreneurship qualities, save time on their undertakings, and hence remain uncompetitive [20]. On top of that, Tanzanian SMEs are faced with a discriminatory loan borrowing as tight conditions and high collateral rate and regulations have not been set to easier accessibility to loan.

Moreover, SMEs in Tanzania are faced with poor and inaccessible infrastructure facilities which involve inadequate and highly cost working premises, communication and transportation network facilities, serviced land warehouses, power problems with insufficient supply, and unreliable and unrealistic cost [21]. In the same vein, it is evidenced that the majority of Tanzanian SMEs are faced with rare or nonexistence or ineffectiveness of a strategic planning process which assists to properly allocate resources, provides a market recognition and growth, increases the chance of achievement of business ventures, and strengthens operations. If they decide, they tend to adopt and orientate themselves to short-term operational strategies with full bias rather than long-term strategic process. However, this brought to reactive decision-making rather than proactive. However, to ensure sustainable performance and development of SMEs, it is essential to understand the reasons for more SMEs strategically failing to improve their performance and to advocate the majority SMEs to apply strategies throughout their entire operations. Nevertheless, SMEs need to resolve various challenges which cause them to mess up in the presentation and implementations of the strategic process set.

Despite the Tanzanian government-led initiative undertaken to empower SME which includes formulation of SME policies, creating a better financial environment for SME to reach the financial institution such as FINCA, PRIDE, SACCOS, SELF, and VICOBA, simplifying the licensing and tax-collection procedures and processes, inviting development partners to support SME, promoting rural industrialization such as SIDO, encouraging joint venture and capacity building, and strengthening institutions and establishment of the University of Dar es Salaam Entrepreneurship Centre in 2001. Also, provision of various business training through vocational education training centers and establishment of the SME department in the ministry responsible for industry and trade in 2003 capacitate entrepreneurs by removing bureaucracy during registration and establishment of the SME credit guarantee scheme managed by the Bank of Tanzania in 2005; to mention a few, SMEs have failed to expand as most of them have remained at the microlevel [22] which created a phenomenon famously referred to as the "missing middle." Researchers have stressed that SME still suffers several challenges in domestic and global market competition. Challenges include lack of capital as a result of lack of collateral to access the loan, failure to compete in international markets, shortage of competent employees to manage an enterprise, underproduction, lack of business training, low payment to an employee, underprivileged supply chain management, low technology, corruption, inadequateness and inaccessibility to local quality materials, poor location, deficient infrastructures, lack of technical knowledge, and inexperience in business with low registration rate. However, despite the tremendous academic effort imposed by various previous selected scholars (Table 3) to publish the SME challenges, there are still more challenges persisting and resulted in more enterprises to stop and quit the business.

From Table 3 above, it is generally recognized that there are more SME challenges of which an individual cannot have enough capacity and capability to address them. It is, 
TABLE 3: Selected studies on SME predominant challenges in Tanzania.

\begin{tabular}{lcc}
\hline Topic of research & Presented challenges & Authors \\
\hline $\begin{array}{l}\text { Business constraints and the potential growth of small } \\
\text { and medium enterprises in Tanzania: a review }\end{array}$ & $\begin{array}{l}\text { Insicient business training, capital constraints, and an } \\
\text { antientrepreneurial culture }\end{array}$ & Mashenene and \\
\hline
\end{tabular}
and medium enterprises in Tanzania: a review

The role of microfinance in promoting small and medium enterprises (SMEs) in Tanzania: empirical evidence from SME holders who have received microcredit from financial institutions in Morogoro

Lack of capital, lack of access to finance, inadequate

business training, weak demand for products, lack of raw materials, and poor infrastructure

Poor partnership, capital constraints, lack of funding, and Mashenene, Macha, lack of collateral and Donge, 2014 sources among the Chagga and Sukuma small and medium enterprises in Tanzania

Nonfinancial constraints to scaling-up small- and medium-sized energy enterprises: findings from field research in Ghana, Senegal, Tanzania, and Zambia Constraints of accessing debt financing from commercial banks among small and medium enterprises in Tanzania: a literature review

Obstacles towards adoption of mobile banking in Tanzania: a review

The challenges confronting small-scale businesses in accessing microfinance services from MFIs case study: rural Tanzania

Inadequate human capacity

Haselip, Desgain, and Mackenzie, 2015

Poor access to debt finance, lack of collateral,

bureaucratic loan procedures, business informality, poor Mashenene, 2015 repayment habits, and corruption

Inadequate network coverage, lack of knowledge of $\mathrm{m}$ -

banking users, lack of enough float of mobile money Rumanyika, 2015 agents, and ATM breakdown and theft

Lack of access to finance

Kimathi, 2015

Export competencies, inadequate and unstable financial capital, reduced production, poor technology, ICT and information, the standard of the products produced by Mpunga, 2016

Examining the factors affecting export performance for small and medium enterprises (SMEs) in Tanzania

the SME, and complicated business laws/regulations

Factors influencing business succession planning among SMEs in Tanzania

Lack of business successors

Magasi, 2016

Challenges facing food processing MSEs in Tanzania: a Lack of capital, lack of raw materials, equipment and qualitative case study of the sunflower oil industry in electricity for processing, tight regulations, poor market Babati, Manyara accessibility, and competition

The lack of business dispute resolution in East Africa: an Lack of access to finance, corruption, and a lack of unresolved impediment to SME development?

Challenges to entrepreneurship development in Tanzania

business training

Ekblom, 2016

The motivation of the business owners

Tillmar, 2016

Isaga and Musabila, 2017

Inborn individual attributes, changing business

environments, competitive activities and location,

inadequate finance, inadequate human and social

Anderson, 2017

Factors affecting small and medium enterprises (SMEs) startup and growth in Tanzania

resources, and a lack of technical and management skills

Financial barriers and how to overcome them: the case of women entrepreneurs in Tanzania

Lack of capital

Lindvert, 2017

Social capital in selected business associations of food processing SMEs in Tanzania and Rwanda: a synthetic based approach

Social-economic constraints towards women business growth in Tanzania

Gamba, 2017

Poor access to market information, technology and finance, weak linkages with support services, and unfavourable policy and regulatory environment

A structuration analysis of small and medium enterprise (SME) adoption of e-commerce: the case of Tanzania

Microfinance traps and relational exchange norms: a field study of women entrepreneurs in Tanzania

Startup motives and challenges facing female entrepreneurs in Tanzania

Poor technology adoption

Nyangarika, 2017

Kabanda and Brown, 2017

Lack of access to capital

Lindvert et al., 2018

Lack of access to finance, gender-related problems, and social and cultural commitments

Isaga, 2019

Bureaucracy, poor physical infrastructures, inferior products, poor services, inadequate business training and skills, little access to information and limited admission Juma and Said, 2019 to technological developments, marketing difficulties, a lack of business training, and inadequate business skills

A review of factors affecting the growth of small and medium enterprises (SMEs) in Tanzania

Financial constraints, capital constraints, poor technology, and tight regulations

Nkwabi J.M. and

Leodger B.,2019

Source: Nkwabi J.M. and Mboya L.B, 2019. 
therefore, advised for the collective efforts among stakeholders in collaboration to governments find the potential strategies to mitigate them.

\subsection{Small and Medium Contractor's Performance.} Previous studies have recognized performance as a hard concept to define, to describe systematically, and to measure. And because of its long-time divergent perception of what constitutes performance in the business arena, researchers have conventionally adopted interchangeably terms such as efficiency, effectiveness, improvement, growth, and success to describe performance. Regardless of that, its interpretative meaning has still not clearly understood to CI stakeholders, such as clients, consultants, contractors, policymakers, employees, firm owners, and investors. Despite the misperception of the term, the weak performance of SMC has been widely reported in various literature studies. Traditionally, the successful performance of SMC was evaluated based on adherence to construction time, budget, quality, safety, and environment to satisfy the client only [23]. However, various visions that have emerged from the operational environment have recently claimed for a widely varied definition of successful performance with multiple constructs to measure performance. The emerged vision contended that not only client satisfaction should be considered as a remarkable feature in analyzing performance in construction; instead, other multiple variables to measure the performance have been proposed. Variables consider recognition of the satisfaction of other stakeholders such as employees, suppliers, and distributors [24] who also play a significant role in attaining adequate performance in the construction projects. However, because of the lack of a definition with unique characteristics in the construction industry, this study will adopt the traditional definition of performance.

The current global construction competitiveness occupied by a continuously changing environment has necessitated the small and medium contractor to struggle to improve the competitive performance advantage of the firms. However, only firms that have attempted to plan, remove unnecessary, identify the proper performance measurement variables, and innovate the remained strategic value processes can enhance improved performance. Performance measurement is defined as a management system of quantifying the efficiency and effectiveness of a project and or an organization. As coined by Chaubey and Subramanian [25], performance management enables organizations to succeed and grow in a situation where the nature of change itself is changing. For performance measurement to be regarded as a useful management process, it should play a role that allows the assessment to be made. It should provide helpful information that can assist in detecting problems and grant judgment against specific predetermined criteria to be performed. Thus, the performance measurement is categorized qualitatively and quantitatively. While quantitative performance measurement involves variables such as financial gain and production measured in terms of many projects executed; qualitative measurement includes the level of discipline to employees, leadership perception, sustainable construction, professionalism, satisfaction based on quality, increased experience, and knowledge through training. However, despite the existence of a performance measurement system model [26], works of the literature have revealed several weaknesses associated with SMC firm's performance in LDCs as described hereunder.

Financial constraints have remained the most critical challenges for SMC creation, survival, and growth. The extent of the financial constraints extends from financial management skills and cash flow problems, loan inaccessibility, and high-interest rates imposed, shortage of technical and competent human resources, nonaccess to plant and equipment, and limited skills in information and technology. In addition, it includes management-related challenges include lack of human resource training, inadequate strategic planning and management knowledge, inexperience, and lack of exposure. Professional and ethical considerable challenges were also identified to hinder performance and growth. These involve changes in design and sparse estimation, lack of accountability, transparency, and prevalence of corruption. However, other noted challenges incorporate lack of infrastructures, weather changes, project suspension by the previous government, political instability and technical performance interference, weak and unrealistic government policy, fragmented or incapacitated institution, and lack of active government policy and strategy [27].

\subsection{Competitive Performance Strategy. A strategy is a firm} process involving the mobilization of its resources and capabilities following the external environment needs to achieve a competitive advantage. It can also be defined as the determination of the long-term goals and objectives of the firm that involves the adoption of sequences of action and the allocation of necessary resources to accomplish the intended targets [28]. The strategy consists of a subdivision of management concerned with the general direction and long-term policy of the business as distinct from shortterm tactics and day-to-day operations. A competitive strategy is a long-term plan targeting adequate performance as a competitive advantage in dealing with strength, weakness, opportunity, and threat (SWOT) facing the firm against another competitor [29]. To put an emphasis, Porter (1985) encouraged the adoption of four variables, strategy, focus, differentiation, and low-cost leadership, to attain a competitive advantage. Differentiation strategies in the construction industry can be realized through quality design that provides unique and valuable services to customers.

However, a hybrid approach (integration of both cost leadership and differentiation element) technique can be embraced to attain competitive advantage. The effectiveness of the hybrid approach can be recognized as a combination of multiple factors that do not easily allow another competitor to identify the potential one and hence reproduce. Thus, this approach is advantageous for a firm to recognize 
improved performance and become competitive. Various theories of competitive advantages have been detailed. Formerly, the theory considered the market-based view embracing industry factor and external market orientation as the primary and dominant determinant of firm performance. Under an industry perspective, the firm's performance could be determined only by the industry structure and the competitive market environment within which it operates. Later, the focus of strategic management analysis changed from the industry structure to the firm's internal structure paradigm considering resources and capabilities as the fundamental features of the resource-based view (RBV) theory [30]. The RBV believes the firm's internal environment as a driver that emphasizes a firm's developed resources in attaining a competitive advantage.

Researchers have acknowledged various competitive advantage strategies that can empower the construction firm for adequate performance. Olson [31] stated that organizational resources involving financial, physical, technological, intellectual, legal, human, organizational, and informational can contribute to defining the organizational structure which when effectively and efficiently utilized can lead to attaining organization performance. Besides, capital, technological, human, and policy-level were mentioned by Zhang et al. [32] as unique and higher-order organizational strategic resources. Recardo [33] documented that market, joint ventures, collaboration, as well as mergers, and acquisition are firm's long-term internal and external planning strategy and the price, place, and promotion as the market forces to be considered for maximization of firm's benefits and internal competencies to improve firm's performance. A study by Odusami [34] identified knowledge and technical skill as the dominant strategy for the firm's improved performance and competitiveness. A joint venture and strategic alliance were suggested by Wang and Yang [35] as a fundamental and preferential strategy for firms' sustainable performance.

Moreover, in their study, Abd et al. [36] recognized strategic planning as an essential performance component since it marks the daily firm operation. On top of that, Hauser et al. [37] admitted that government funding and support, team building, staff competence and cohesiveness, organizational culture and training, and continuing education are fundamental strategies for organization improvement. Iyagba and Ojuola (2004) cemented on management practice competence as an additional strategy for continued firm growth. On top of that, Shaukat et al. [38] coined that a proactive organizational strategy is a fundamental strategy which positively and significantly encourages social and environmental performance improvement. Moreover, other strategies proposed include financial stability and firm owner's characteristics as well as human resource capacity building. The possible strategies identified follow within market-based and resource-based view theories. However, the remark for the new study argued for the prioritization of the identified strategies. Table 4 provides a summary of organizational strategy for the firm's performance improvements.
2.4. Business Process Re-Engineering (BPR). The effect of globalization caused intensive local-global competition and the change in technology have forced various firms to adopt the BPR management technique. The technique has enabled the elimination of some processes and finding not only new but also an innovative and strategic process to attain more success [39]. Re-engineering is a valuable tool that has been implemented as a significant driver toward changes within many organizations. BPR was identified to facilitate reinventing the traditional technique of doing work. It also assists in changing a systemic process and behavioral problems to become competitive, to improve the capacity and capability of the firm, and to satisfy customers, employees, and other stakeholders who wish for dramatic results that may help a firm to survive in the long term. A successful implementation of BPR has resulted in noticeable benefits as a competitive advantage to the organization through customer satisfaction, reducing cost, increased productivity, superior flexibility, and improved coordination. BPR was highly adopted and well-practiced in the manufacturing industry sector, banks, and education. In CI, it has attained a low satisfactory level due to its nonexistence practically rather than in the literature. Reasons mentioned for its little rate of adoption were nonimplemented for the majority of re-engineered initiatives that indicated the resistance to change together with the uniqueness of the industry [40].

$\mathrm{BPR}$ is a dramatic, radical redesign that focuses on strategic processes aiming to attain substantial improvements in terms of cost, time, and quality of service. It incorporates the envisaging of new strategic processes, redesign, and implementation of the changes in all its complex technological, human, and organizational diminutions. Various BPR definitions have been provided. The bestadopted definition encompasses three fundamental issues. The first issue involves rethinking, which describes an understanding of the SMC business, including the characteristics, current nature of the operation, and the future changes required to attain competitive advantage for business survival. The second describes the radical redesign, which makes the firm forget the usual way of working and think critically only on the innovative and strategic business processes. The last one reflects on critical aspects of pursuing a process's perspective. Various major components were identified as fundamentals for change in an organization including organization's structure, culture, management process, people, strategy, and information technology (IT) as an enabler and essential ingredients for change [41]. However, for a BPR to play a strategic value in handling substantial change, it should comprise a strategy as a new vision that creates an operational capability, re-evaluates, and redefines the strategies for a new product and or service. Thus, the investigation of the characteristics of Tanzania construction firm's project performance together with the tentative literature on construction business process reengineering from LDC has provided a draft set of strategic construction processes (Table 5) contributing to firm's performance improvement. 
TABLE 4: Selected organizational strategies (OSs) considered in the current study.

\begin{tabular}{lc}
\hline S/N & Organizational strategies \\
OS1 & Establish and provide support to firms to access finance and loan \\
OS2 & Adopt a low bidding price strategy \\
OS3 & Adhere to small firm operational cost \\
OS4 & Invest in technology and establish technology transfer centre \\
OS5 & Optimize available local quality construction materials \\
OS6 & Facilitate training for capacity building \\
OS7 & Adopt joint venture and partnership with an overseas firm \\
OS8 & Policy formulation of construction bank establishment \\
OS9 & on tax reduction of imported construction equipment and materials \\
OS10 & Enhance networking to share experience \\
OS11 & Ensure resource availability, allocation, and utilization \\
OS12 & Training certification by government \\
OS13 & Ensure employee's right working environment \\
OS14 & Ensure resources upgrading or improving \\
OS15 & Timely strategy review \\
OS16 & Ensure client satisfaction \\
OS17 & Policy on compulsory joint venture \\
OS18 & Establish construction equipment centre \\
OS19 & Employ competent and technical employees \\
\hline
\end{tabular}

TABLE 5: Selected strategies for construction core process (SCP) considered in this study.

\begin{tabular}{lc}
\hline S/N & Strategic core process \\
\hline SCP1 & Employ a competent design expert \\
SCP2 & Integrate design team with related department \\
SCP3 & Abide to design standard and specification \\
SCP4 & Allocate a balanced design resource \\
SCP5 & Develop a design process management protocol \\
SCP6 & Adopt constructability concept to avoid reworks \\
SCP7 & Adherence to procurement ethics and code of conduct \\
SCP8 & Information, communication, and record management \\
SCP9 & Contract, risk, and dispute management \\
SCP10 & Ascertain to proper resource (finance, schedule, material, and equipment) management \\
SCP11 & Adopt an electronic-tendering system to reduce a bidding cycle time \\
SCP12 & Select a competent, experienced, and accessible contractors \\
SCP13 & Categorize works to identify appropriate contract type, negotiation, and management \\
SCP14 & Provide enough information on contact conditions \\
SCP15 & Review the conflicting procurement policy and regulations \\
SCP16 & Adoption of modern construction technique \\
SCP17 & Healthy, safety, and welfare management \\
SCP18 & Quality assurance (standard, specification, or codes) \\
SCP19 & Reduce waste and adopt a sustainable construction \\
SCP20 & Recognize and motivate the design expert \\
SCP21 & Gather a complete design requirement for client and stakeholders
\end{tabular}

Note: SCP = strategic core process representing design, procurement, and construction management; source: researchers.

BPR was adopted in this study to help to identify various strategic construction processes. It also assisted in indicating the chronological phase of the research and helped to develop the conceptual framework aiming to improve SMC performance. Kwakye [42] described that the first step was undertaken to review the prevailing firm's SCP (value activities). The second step aimed to measure, assess, and identify the weakness indicators within the prevailing ("AsIs") process. The third stage of the study intends to establish the factors to be considered to improve the performance standard. The last step aimed to identify and rank to prioritize strategies for performance improvement.
2.5. A Conceptual Framework of the Study. The framework has adopted the business process re-engineering concept that involves analysis, formulation, and implementation of strategies to attain improved performance. The structure (Figure 1) indicates four steps that should be followed in this study to achieve the study objectives. The first step involves a literature review conducted to identify performance weakness indicators, firm attributes, performance measures, and strategies identified by various scholars. The second step provides the general concept of business process re-engineering; the third step describes the data collection procedure and analysis. The last step describes the structural 


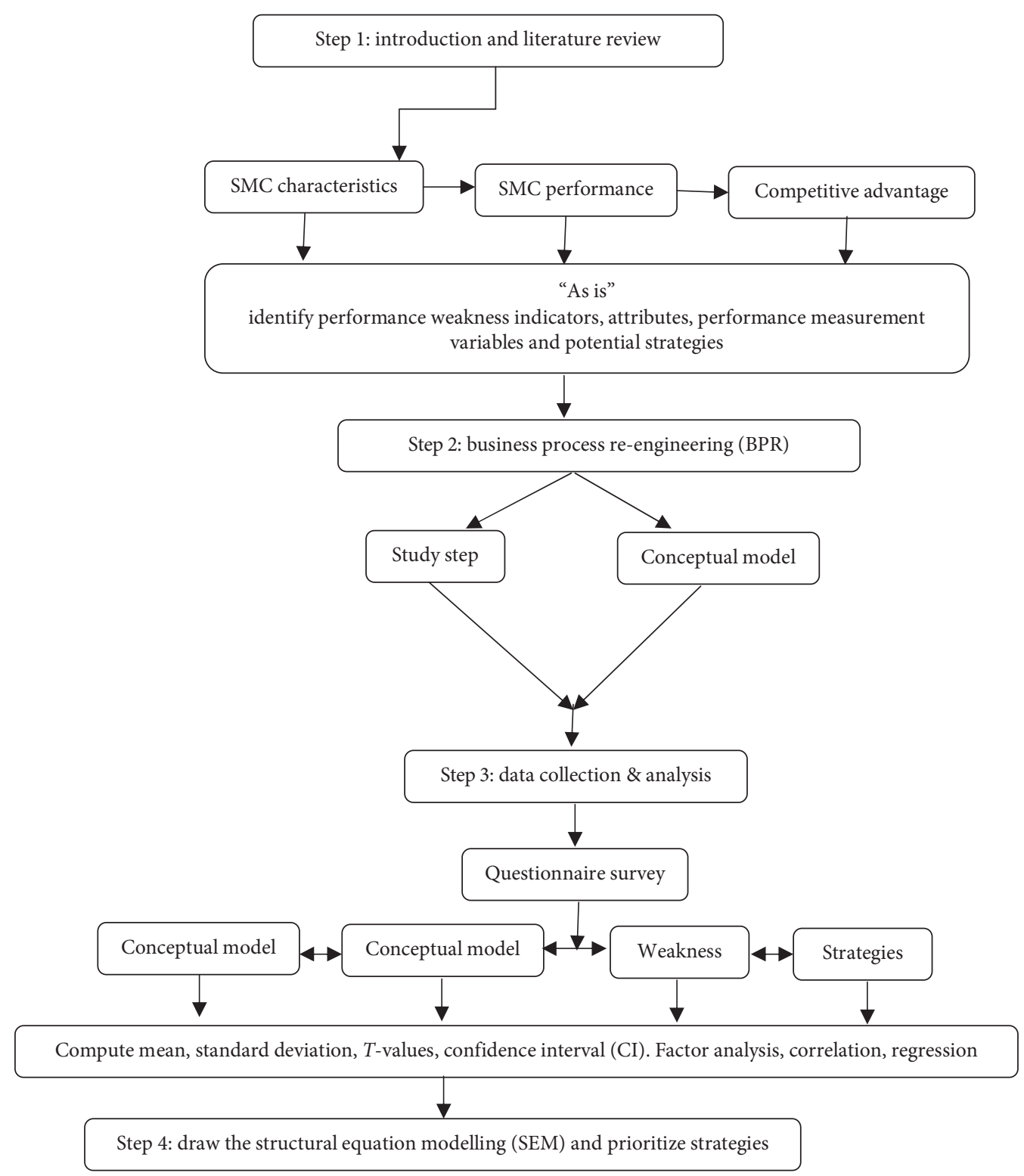

Figure 1: A framework to prioritize strategies.

equation modelling (SEM) that portrays the correlation between prioritized strategies. A conceptual framework of the study (Figure 2) presents the author's synthesis to the previous literature and the adopted study philosophy intending to describe a phenomenon. It draws out the arrangement of action and activities required in the course of the study to attain the objectives. The conceptual framework reveals the study variables and their relationship, which provides a conceptual distinction towards prioritizing strategies in achieving an improved performance of SMC in LDC.

\subsection{Materials and Methods}

2.6.1. Survey Method. This study adopted a survey method comprising a questionnaire tool and an interview. It intends to collect and assess the characteristic opinions of a large population based on a smaller sample of respondents in the case study of Tanzania construction market environment representing LDCs. An interview facilitated the discussion with respondents to understand the model, identify a strategy and strategic construction processes, indicators for SMC weakness, and the potential "To-Be" process, and prioritize strategies for substantial performance improvement.

Because of little knowledge and practice of BPR technique in the local construction market in Tanzania, the reliable option was to adopt a systematic process (SP). A systematic process assisted in getting respondents from the firm with enough experience, the capability to adapt, analyze, measure the performance process, identify the potential "To-Be" strategic construction process, conduct training and research studies, and pay for performance improvement to improve the outcomes. From the 


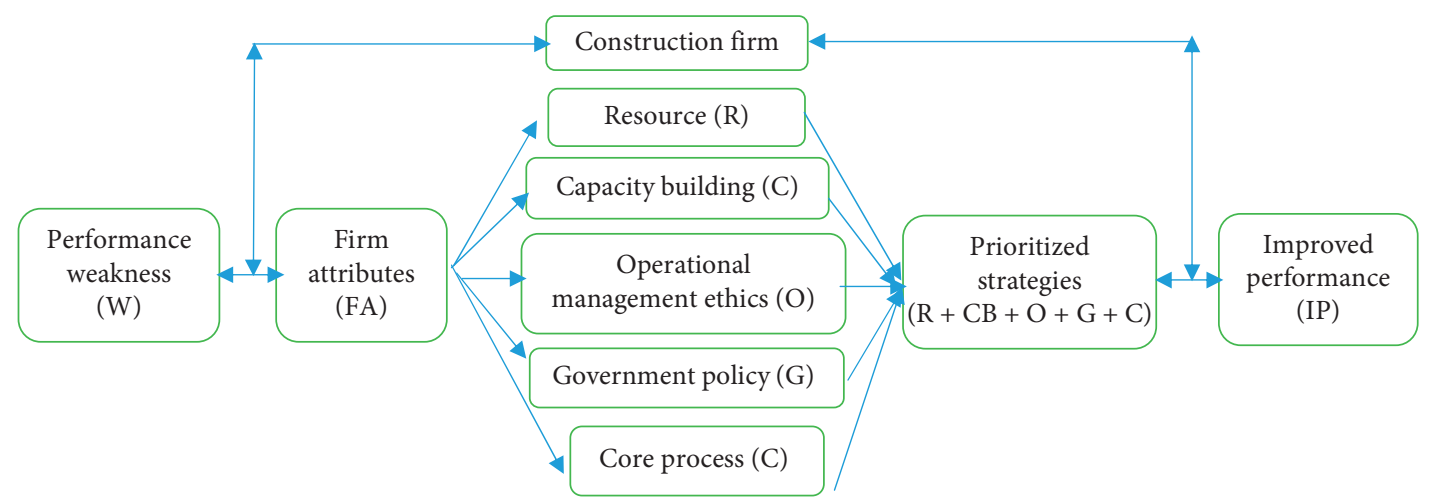

FIgURE 2: A conceptual framework of the study.

Contactors Registration Board (CRB) authority, a list of registered firms was obtained. The prequalification of the systematic process was performed through a preliminary interview. Twenty (20) employees having more than ten years of experience from the different firms were purposively selected based on their unique characteristics, as referred to the same categories of registration. The interview facilitated the identification of twenty-eight (28) firms with a total population of 693 employees. Taro Yamane's formula was applied in the equation below to compute the minimum sample size for the study resulted in 253 respondents:

$$
\text { sample size }(n)=\frac{N}{(1+N e)^{2}}=253,
$$

where " $n$ " is the corrected sample size (the minimum number of respondents required), " $N$ " is the population size (the tootal number of employees on identified firms), and " $e$ " is the margin of error $(\mathrm{MoE})$ representing a level of precision or acceptable sampling error. For this study, the confidence level was assumed to be $95 \%$ within an acceptable alpha level $(\mathrm{MoE}=0.05)$ [43].

2.7. Questionnaire Design. A structured questionnaire tool was administered to respondents to collect the cross-sectional data to obtain an opinion on strategies to be established, aiming to attain performance improvement of local against overseas firms. It has been divided into five sections: Section 1 intended to collect the respondent's demographic information. Section 2 aimed to get an opinion on performance measures/indicators used to identify the current performance weaknesses. Section 3 intended to capture information and understanding about the firm attributes for performance improvements. Section 4 meant to identify potential strategies under the business process re-engineering philosophy embraced from the core construction process, and Section 5 aimed to get an opinion on the prioritization of listed strategies on the Likert scale for performance improvement.

The binary Likert scale number (from $1=$ strongly disagree to $5=$ strongly agree) intended to indicate the numerical ranks only. However, a continuous average rating with the proposed ordinal value level was used to help accurately translate the findings of the respondent on a fivepoint Likert scale. The level of each item was determined using the formula: (highest point - the lowest point in the Likert scale) divide by the number of the levels used [44]. However, the following group Likert scale points were used: 1 to $\leq 1.8$, represented strongly disagree; 1.81 to $\leq 2.6$, represented disagree; 2.61 to $\leq 3.4$, described moderate; 3.41 to $\leq 4.2$, represented agree; and $4.21 \leq 5$, expressed strongly agree.

Furthermore, a pilot study was performed to twenty professionals selected at random from the antecedently identified respondent supported by their seniority and experience. It aimed to test and establish errors as well as wrong, unnecessarily wordy, and unambiguous terms. The study helped to review the questionnaire form and to produce an elaborative and straightforward one to be understood by respondents. The pilot study resulted in a better study tool for further steps. However, later on, the same respondent was contacted for face-to-face and mobile interviews on prioritization strategies to improve performance. A total of two hundred fifty-three (253) copies of questionnaires written in English and translated in local Swahili language were administered (from October 2019 to January 2020) to respondents employed within the identified firms while considering their qualifications, expertise, availability, accessibility, and willingness to participate in the study. To ensure that respondents understand the research well, a brief explanation of the questionnaire contents was provided by the researcher that increased an understanding of the topic and decreased the chance of misinterpretation. However, very few (20) respondents who were absent during face-to-face interviews, their emails, and social media networks such as WhatsApp, WeChat, and calls were used for questionnaire distribution and administration. A total of 203 (80.24\%) well-attended questionnaires were used for data analysis.

The respondent of the study comprised $54.4 \%$ degree graduate, $33.1 \%$ master, and $12.5 \% \mathrm{PhD}$ levels. Besides, $59.3 \%$ of respondents represented engineers, $10.4 \%$ architects, $17.8 \%$ quantity surveyors, and $12.5 \%$ other professionals. High-ranked respondents were involved in the study, with $38.9 \%, 20.7 \%, 13.8 \%$, and $26.6 \%$ representing 
general managers, project managers, departmental managers, and site engineers, respectively. Besides, $34.6 \%$ of respondents represented a consultancy firm, 52.7\% represented contractors, and $8.2 \%$ represented clients while the rest $(4.5 \%)$ represented other CI stakeholders. The analysis of demographic characteristics has demonstrated the presence of experienced, skilled, and knowledgeable respondents from small and medium local construction firms registered in the first-class level who have implied to provide reliable information for the study.

2.8. Data Analysis. Data coding, entry, editing, and analysis were performed using Statistical Packages for Social Science (SPSS 20). Since the scale and measures of this study were adapted and adopted from the literature, it was crucial to test them with intended collected sample data of this study. Construct validity was performed to measure the extent to which all items on a scale measure the same construct and reduce different errors. Also, data examination was conducted to test the internal reliability of the 5-point Likert scale. The test aimed to check if the questionnaire instrument provides the same results (equivalence) at different sets of tests. The analysis results (Table 6) yielded Cronbach's alpha coefficient of $0.883,0.752,0.814,0.831,0.773,0.800$, and 0.811 representing resources, capacity building, operational, government policy, design, procurement, and construction management, respectively, of the strategies of the five-point Likert scale. However, the computed value was found to be above the recommended and acceptable value of 0.7 [45].

Furthermore, principle component analysis (PCA) was performed to test for Kaiser-Meyer-Olkin (KMO) as a measure of sampling adequacy for intended strategies. The result of the analysis shows Bartlett's test of sphericity of approximate chi-square (1966.358), KMO (0.8347), and attaines a (0.000) significant level, which indicates that the correlation matrix is not the identity matrix. The value of KMO obtained has suggested the suitability of the samples for factor analysis [46]. Descriptive statistical analysis using mean, standard deviation, percentages, and frequencies was applied and presented using charts, pictorial, and graphical representation for quantitative information analysis. Cross tabulation and statistical tests such as $T$-test and bivariate correlation were also used to show the confidence intervals (CIs) and the relationship between variables. Two statistical analysis techniques (ranking and factor) were performed to prioritize the strategies using the Statistical Packages of Social science (SPSS 24). However, SPSS-AMOS was used to generate the structural equation modelling (SEM) that helped to quantify the relationship among multiple variables used to improve SMC's performance.

\section{Results and Discussion}

3.1. Performance Measurement Variables. The response ranked in percentage was used to identify the most significant factor to measure the performance. The findings of the study (Figure 3) indicated the most top seven (7) ranked variables to be preferred to measure the performance of the local firm in LDC's construction market. These include an increased number of the employee in the firm $(A=56.2 \%)$; adherence to standard and specification that reflect quality ( $B=62.8 \%)$ and hence value for money $(C=53.3 \%)$; increase of firm investment $(E=53.3 \%)$ and adoption of new technology $(G=56.2 \%)$; completion of projects within the specified contract time $(H=59.1 \%)$; and attaining intended firm objectives $(K=51.8 \%)$. The preferential variables identified in this study have fallen in line with indicators documented as the "iron triangle" [47]. During a face-to-face interview, respondents mentioned the increased number of employees in the firm, adoption of new construction techniques such as building information modelling (BIM), artificial intelligence (AI), offsite construction (OC), use of drones and robots, and the increased rate of investment of the firm as the potential performance variables in LDC. The least three ranked variables involving the increased social performance $(D=15.3 \%)$, employee's salary increase $(F=16.8 \%)$, and economic growth $(J=21.2 \%)$, as well as environmental sustainability $(I=17.5 \%)$, were less considered. However, it was noted during the interview that many CI stakeholders in LDC are faced with sustainable built environment challenges that include poor understanding and awareness. However, despite the employee's role in attaining a firm's performance improvement, their welfare and earnings were least considered.

3.2. Performance Weaknesses Indicators. Indicator identification that led to weakness in the performance of firms in the local competitive markets was to be identified in this study. The one-sample T-test analysis was used to compare the mean of 23 weakness indicator variables. The findings recognized twelve (12) highly scored mean variables. Indicators were grouped into four (4) clusters, namely, resource (4-R), operational (3-O), professionalism (2-P), and government policy (3-GP) abbreviated as (ROGPP) whose $T$ values, standard deviations, mean, and confidence interval at 95\% (Table 7) are represented.

The first and foremost indicator is a resource that involves absence or inadequateness of essential resources, including finance, materials, competent labor, and plant and equipment. Finance is believed to be the foremost powerful resources and one of the potential competitive advantages for any firms' growth. The prevailing bureaucracy to local firms in accessing loans has been a critical cause of lack of finance. However, high-interest rates, collateral, and loan processing fee conditions imposed on firms have extended difficulties to access the loan. Besides, a lack of research on quality local materials has hindered the identification of local materials that may assist in reducing cost and increasing profit. On top of that, shortages of skilled labor were also identified as a performance weakness indicator. Since most firm owners have little knowledge of CI, they tend to ignore employing competent and skilled labor. Thus, they opt for cheap work, which always led to inadequate performance.

The second identified indicator was operational and management, which includes lack of training. Thus, it is 
TABLE 6: Convergent validity test result.

\begin{tabular}{lccccccc}
\hline Variables & R & CB & OP & GP & DE & PR & CM \\
\hline AVE & 0.663 & 0.661 & 0.648 & 0.664 & 0.574 & 0.709 & 0.640 \\
CR & 0.903 & 0.853 & 0.879 & 0.888 & 0.754 & 0.879 & 0.742 \\
Cronbach's alpha & 0.883 & 0.752 & 0.814 & 0.831 & 0.773 & 0.800 & 0.811 \\
Rho_A & 0.834 & 0.732 & 0.769 & 0.835 & 0.813 & 0.838 & 0.883 \\
Result remarks & Recognized & Recognized & Recognized & Recognized & Recognized & Recognized & Recognized \\
\hline
\end{tabular}

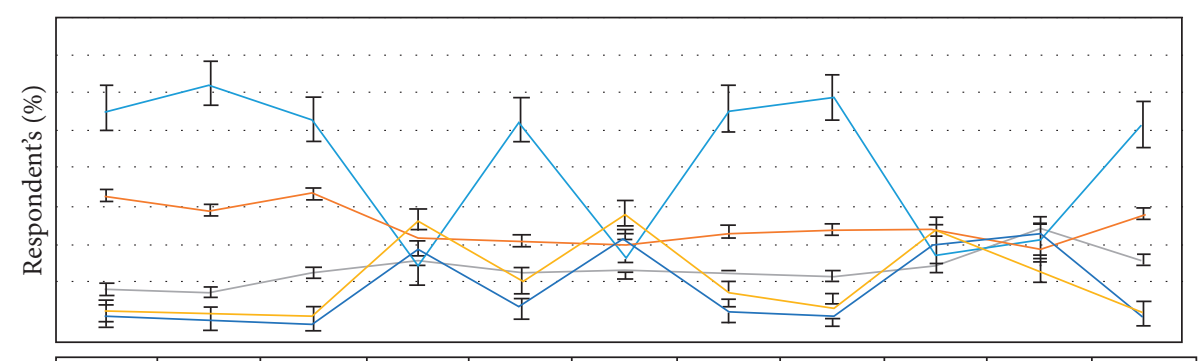

\begin{tabular}{|c|c|c|c|c|c|c|c|c|c|c|}
\hline$A$ & $B$ & $C$ & $D$ & $E$ & $F$ & $G$ & $H$ & $I$ & $J$ & $K$ \\
\hline 56.2 & 62.8 & 53.3 & 15.3 & 53.3 & 16.8 & 56.2 & 59.1 & 17.5 & 21.2 & 51.8 \\
32.8 & 29.2 & 33.6 & 22.6 & 21.2 & 19.7 & 23.4 & 24.1 & 24.1 & 19.0 & 28.5 \\
8.0 & 7.3 & 12.4 & 16.1 & 12.4 & 13.9 & 11.7 & 11.7 & 13.9 & 24.1 & 16.1 \\
2.2 & 0.7 & 0.7 & 26.3 & 10.2 & 28.5 & 6.6 & 3.6 & 24.1 & 13.1 & 2.2 \\
0.7 & 0.0 & 0.0 & 19.7 & 2.9 & 21.2 & 2.2 & 1.5 & 20.4 & 22.6 & 1.5 \\
\hline
\end{tabular}

Performance measurement variables

$\begin{array}{ll}\text { — Strongly agree } & \text { Disagree } \\ \text { Agree } & \text { Strongly disagree } \\ \text { Moderate } & \end{array}$

Figure 3: Respondent's opinion on performance measurement. $A=$ increased number of employees; $B=$ quality increases; $C=$ attain value for money; $D=$ increased social performance; $E=$ increased return on investment and asset (ROI \& ROA); $F=$ employee's salary increase; $G=$ new technology adoption; $H=$ timely project completion; $I=$ environmental sustainability; $J=$ employee's economic growth; $K=$ profitability.

TABLE 7: Performance weaknesses indicators.

\begin{tabular}{|c|c|c|c|c|c|c|}
\hline \multirow{2}{*}{ Cluster } & \multirow{2}{*}{ Indicators } & \multirow{2}{*}{$T$ values } & \multirow{2}{*}{$\mathrm{SD}$} & \multirow{2}{*}{ Mean } & \multicolumn{2}{|c|}{$95 \% \mathrm{CI}$} \\
\hline & & & & & Lower & Upper \\
\hline $\mathrm{R} 2$ & Financial constraints and cash flow problem & 32.29 & 1.00 & 2.49 & 2.33 & 2.64 \\
\hline $\mathrm{R} 3$ & Lack of local quality materials & 30.75 & 1.02 & 2.41 & 2.26 & 2.57 \\
\hline $\mathrm{R} 4$ & Shortage of competent human resource & 28.62 & 1.12 & 2.46 & 2.29 & 2.63 \\
\hline R7 & Nonaccess to plant and equipment & 30.53 & 1.03 & 2.43 & 2.27 & 2.58 \\
\hline $\mathrm{O} 1$ & Lack of on-job training & 17.33 & 1.03 & 1.38 & 1.22 & 1.54 \\
\hline $\mathrm{O} 4$ & Lack of general management knowledge & 18.62 & 0.99 & 1.42 & 1.27 & 1.57 \\
\hline O6 & Poor strategy and strategic planning & 15.63 & 1.11 & 1.34 & 1.17 & 1.51 \\
\hline $\mathrm{P} 2$ & Changes in design & 18.35 & 0.99 & 1.40 & 1.25 & 1.55 \\
\hline $\mathrm{P} 3$ & Prevalence of unethical conduct & 14.85 & 1.12 & 1.28 & 1.11 & 1.45 \\
\hline GP2 & Weak and unrealistic government policy & 18.86 & 0.95 & 1.38 & 1.23 & 1.52 \\
\hline GP4 & Lack of government policy and strategy & 17.34 & 1.02 & 1.36 & 1.21 & 1.52 \\
\hline GP5 & Lack of infrastructures & 16.26 & 1.15 & 1.44 & 1.27 & 1.62 \\
\hline
\end{tabular}

Note: $\mathrm{R}=$ resources; $\mathrm{OM}=$ operational and management; $\mathrm{P}=$ professionalism; $\mathrm{GP}=$ government policy .

recommended to implement on-job training that will assist to improve the performance. Professionalism is the third cluster of indicators identified, which frequently involves changes in design during construction activities as well as the presence of malpractices throughout the entire construction processes. Most respondents warned the exceedingly malpractices attitudes which occur throughout the construction process as a whole. Many firms were noted to involve in corruption during the tendering process and design to construction processes, which have always led to poor construction projects. The last group of indicators acknowledged lack and weak unrealistic government 
policies, strategies, and infrastructures to facilitate performance improvements to local firms compared to foreign firms. However, the government policy was identified to enable the creation of a better business working environment, availability of local materials, certifying training, capacitating the institution, and enforcing policy and strategy implementation.

3.3. Firm Attributes for BPR. The identification of the firm attribute intended for BPR was among the vital stage of the study. Respondents were obligatory to give the opinions on ten characteristics provided using five-point Likert scales described in 3.2. The findings discovered five (5) attributes scored above the average computed mean value of 0.64 . Factor analysis facilitated grouping the attributes into only two generated clusters. Names were given to cluster for easy and straightforward interpretation. Competent and experienced team, resources, and information were grouped in resource $(\mathrm{R})$ cluster while training and best management practice were grouped into the operational and management $(\mathrm{OM})$ cluster. The combination of the two cluster names can be abbreviated as (ROM). The observation from the finding depicts that competent and experienced team to lead changes $(M=0.67 ; t=11.54 ; \mathrm{SD}=0.73 \mathrm{CI}=0.53-0.76)$ was amongst the critical attributes towards performance improvement. The construction team should involve experienced, talented, visionary, and self-esteemed individuals with cross-functional roles committed to rethinking on changes. Training to capacitate knowledge to an employee $(M=0.76 ; t=11.69 ; \mathrm{SD}=0.62 ; \mathrm{CI}=0.47-0.66)$ was secondranked since it enhances better human resource practice. Adequate resources to support changes $(M=0.78 ; t=12.37$; $\mathrm{SD}=0.81 ; \mathrm{CI}=0.65-0.90)$ were noted as extremely important due to its role to support the whole re-engineering process. Moreover, best management practices $(M=0.89$; $t=9.29 ; \mathrm{SD}=0.57 ; \mathrm{CI}=0.32-0.50)$ were mentioned to facilitate re-engineering of the firm to attain improved performance. However, correct information channel and sharing on changes $(M=0.11 ; \quad t=15.71 ; \quad \mathrm{SD}=0.91$; $\mathrm{CI}=0.96-1.24)$ were mentioned to allow the dissemination of information to policies and "To-Be" processes for changes.

3.4. Ranking of Strategies. The survey results of combined organizational and construction core processes related strategies (Tables 4 and 5) using SPSS 24 to compute descriptive information on strategies generated a descending mean score and standard deviation of each strategy (Table 8). Thinking on finding the best measure of decision (criterion), the use of a Likert psychometric scale during analysis to measure opinion or scale response became the best criteria towards prioritizing strategies. Since this study adopted a 5point Likert scale, only strategies ranked equal to or above the scale value of 4 (implying effective or important) were prioritized for performance improvement. However, whenever two or more strategies fall within the same mean scale value, the one with a lower standard deviation was prioritized and assigned ranked the most.
The ranking process generated a total of twenty-seven (27) potential strategies for performance improvement. During ranking, none of the reviewed group of strategy dominated. The finding suggests that, for any firm in LDC to attain an improved performance, both organizational strategy and process-related strategies should be considered of paramount importance. Researchers thought significant to discuss only the topmost ten and least five strategies to represent the implication of the findings. However, strategies representing the same practical implication during ranking were thought for generalization during the discussion.

The first six high ranked and the ninth strategies with corresponding mean (OS1; mean $=4.49$; $\mathrm{SCP} 10$; mean$=4.46 ;$ SCP12; mean $=4.43 ;$ SCP $1 ;$ mean $=4.42 ;$ SCP 4 ; mean $=4.41$; OSC19; mean $=4.40$; OS11; mean $=4.38$ ) were fundamentally and importantly resources recognized. It can be seen from Table 8 that resource (finance, time, material, equipment, contractors, design expert/consultant, and employees) availability, accessibility, allocation, utilization, balanced, competence, technical, management, and support were considered significant to facilitate the realization of improved performance. The essential design expertise has reached more shortage in undertaking project evaluation before and during the design stage. Besides, similar to many developing countries, production, supply, and management of building materials have occupied the highest position on the list of construction firm impediments. In the same vein, from the result history of structural adjustment programs undergone within LDC, the programs consistently involved cuts in governments' capital investment, which led to a prolonged severe strain and chronically shortage of public funds. The situation caused insufficient gross domestic savings, which has, for decades, resulted in a prevalent shortage of financial resources that could finance construction projects executed by many SMCs [48].

Moreover, most contractors who employ labor are smallto-medium firms with limited organizational, technical capacity and capability and lack resources to invest in human capital development [49]. For the SMC to improve and successfully perform construction projects well, skilled labor is one of the vital strategies. Several construction projects have attained unsuccessful performance due to a qualified labor shortage. Ways must be anticipated to structure resource strategies to accommodate the challenges. However, governments should support the SMC to reduce resource availability and accessibility challenges to realize improved performance.

Training for capacity building $($ OS6; mean $=4.40)$ was ranked the seventh strategy compulsory to improve SMC performance. Shortage of appropriate qualified and competent workforce has been identified as one among the persisted critical problems accelerated by the shortage of skills/training. Windapo [50] noted that the level of supply of skilled labor is attributed to the lack of relevance firstquality rate of basic education training. However, to improve the skilled labor shortage problem in the construction industry, a significant change in the construction education curriculum based on training delivery style, recruitment, 
TABLE 8: Ranking of prioritized strategies for performance improvement.

\begin{tabular}{|c|c|c|c|c|}
\hline Code & Strategies & Mean & Std. deviation & Ranking \\
\hline OS1 & Establish and provide support to firms to access finance and loan & 4.49 & 0.65 & 1 \\
\hline SCP10 & Resource (finance, schedule, material, and equipment) management & 4.46 & 0.65 & 2 \\
\hline SCP12 & Select a competent, experienced, and accessible contractors & 4.43 & 0.58 & 3 \\
\hline SCP1 & Employ a competent design expert & 4.42 & 0.95 & 4 \\
\hline SCP4 & Allocate a balanced design resources & 4.41 & 0.62 & 5 \\
\hline OS19 & Employ competent and technical employees & 4.40 & 0.62 & 6 \\
\hline OS6 & Facilitate training for capacity building & 4.40 & 0.66 & 7 \\
\hline OS7 & Adopt joint venture and partnership with overseas firm & 4.39 & 0.72 & 8 \\
\hline OS11 & Ensure resource availability, allocation, and utilization & 4.38 & 1.00 & 9 \\
\hline SCP21 & Gather a complete design requirement for client and stakeholders & 4.37 & 0.75 & 10 \\
\hline SCP7 & Adherence to procurement ethics and code of conduct & 4.35 & 0.71 & 11 \\
\hline SCP2 & Integrate design team with another related department & 4.33 & 0.78 & 12 \\
\hline OS5 & Optimization of local quality construction materials & 4.31 & 0.65 & 13 \\
\hline OS3 & Adhere to low-firm operational cost & 4.30 & 0.58 & 14 \\
\hline OS4 & Invest on technology and establish technology transfer centre & 4.29 & 0.80 & 15 \\
\hline OS18 & Establish construction equipment centre & 4.27 & 0.71 & 16 \\
\hline SCP15 & Reviewing the conflicting procurement policy, laws, and regulations & 4.25 & 0.84 & 17 \\
\hline OS13 & Penalizing and blacklist firms engaged in malpractices & 4.24 & 0.95 & 18 \\
\hline SCP11 & Adopt an electronic-procurement system to reduce a bidding cycle time & 4.21 & 0.81 & 19 \\
\hline SCP18 & Quality assurance (standard and specification) & 4.17 & 1.09 & 20 \\
\hline OS17 & Policy on compulsory joint venture & 4.14 & 0.83 & 21 \\
\hline OS2 & Ensure employee's good working environment & 4.14 & 0.92 & 22 \\
\hline OS12 & Training certification by government & 4.12 & 0.83 & 23 \\
\hline OS9 & Enforce tax reduction policy of imported construction equipment and materials & 4.09 & 0.69 & 24 \\
\hline OS8 & Policy formulation of construction bank establishment & 4.05 & 0.73 & 25 \\
\hline SCP16 & Adoption of modern construction technique & 4.04 & 0.79 & 26 \\
\hline OS10 & Enhance networking to share experience & 4.01 & 0.80 & 27 \\
\hline SCP20 & Recognize and motivate the design expert & 3.63 & 0.69 & 28 \\
\hline SCP3 & Abide to design standard and specification & 3.63 & 0.85 & 29 \\
\hline SCP5 & Develop a design process management protocol & 3.58 & 1.03 & 30 \\
\hline SCP6 & Adopt constructability concept to avoid reworks & 3.53 & 0.88 & 31 \\
\hline SCP14 & Provide enough information on contract specification and conditions & 3.51 & 0.81 & 32 \\
\hline SCP13 & Categorize works to identify appropriate contract type & 3.47 & 0.77 & 33 \\
\hline SCP8 & Information, communication, and record management & 3.43 & 1.13 & 34 \\
\hline SCP9 & Contract, risk, and dispute management & 3.41 & 0.81 & 35 \\
\hline SCP19 & Reduce waste and adopt a sustainable construction & 3.37 & 1.77 & 36 \\
\hline OS14 & Ensure resource upgrading or improving & 3.36 & 0.85 & 37 \\
\hline OS15 & Timely strategy review & 3.33 & 0.84 & 38 \\
\hline OS16 & Ensure client satisfaction & 3.28 & 0.98 & 39 \\
\hline SCP17 & Healthy, safety, and welfare management & 3.23 & 0.69 & 40 \\
\hline
\end{tabular}

Note: OS1, 4, 19, 5, and 18 represent resources; OS6, 10, and 7 represent capacity building; OS17, 12, 9, and 8 represent government policy; OS11, 3, 13, and 2 represent operational and management; SCP1, 21, 4, and 2 represent design; SCP15, 11, and 7 represent procurement.

and certification needs to be given the necessary attention. Respondents contended to the government to take charge of certifying the training $(\mathrm{OS} 12$; mean $=4.12)$. However, most LDC governments need to invest in vocational and technical education programs and teach students to be able to analyze and solve problems while considering environmental, ethics, and code of conduct.

Furthermore, joint venture and partnership with overseas firms $(O S 7$; mean $=4.39)$ was ranked among the top strategy to enable an improved performance since it enhances resource, knowledge transfer, technology, and experience sharing that creates a competitive advantage to construction firms. Joint venture and partnership comprise a binding contractual relationship between two or more independent firms aiming to share their resources to achieve competitive productivity within the construction market.
Most contractual joint venture and partnership between construction firms are faced with various challenges such as misunderstanding and conflict led by poor allocation and management of the fund by either partner, loss of communication and trust among partners, termination of the contract by the client, delay of payment, low experience, and capacity as well as nonadherence to the condition of the contract of either partner. Minja et al. stressed that a suitable joint venture and partnership agreement is an essential strategy for performance improvement. Clear contractual terms and conditions should be concrete, precisely, and specified to be understood by all partner(s) and other stakeholders responsible for the contract [51]. During the interview, respondents proposed the government to enforce policy on a compulsory joint venture (OS17; mean 4.14) between SMC and overseas firms. It is suggested that large 
and complex public financed projects should necessarily be awarded to foreign firms having contractual joint venture agreements with local SMC. This is predicted to improve performance.

Other potential strategies highly ranked in the list to facilitate attaining an improved performance include gathering complete design information for client and stakeholders' requirements $(\mathrm{SCP} 21$; mean $=4.37)$. Design can be defined as a strategic approach for an individual to achieve a different intended expectation. Always, errors in design can cause failure in construction and project progress at large. The misinterpretations during design as a result of lack of thoroughly collected design requirement information may lead to design errors that reduce the quality of construction works and becomes the source of project's cost overruns and delays. Different design causal factor was recognized in various literature studies. These include lack of skills and experience, schedule pressure, little design completion time, poor communication during design, and lack of client and end-user requirements [52]. However, a complete gathering of design information is considered among the potential strategies needed to avoid errors, which lead to reduced construction performance. Therefore, preventive measures to reduce the design errors are necessary to realize improved performance.

Other strategies including health, safety, and welfare management (SCP17; mean=3.23), ensuring client satisfaction (OS16; mean $=3.28$ ), timely strategy review (OS15; mean $=3.33)$, resource upgrading $(\mathrm{OS} 14$; mean $=3.36)$ and reducing waste, and adoption of sustainable construction (SCP19; mean $=3.37$ ) were least prioritized. Surprisingly, health and safety as well as sustainable construction were documented as an essential strategy in different works of the literature since they are fundamental to support human resources [53]. Equally important, sustainable construction has been a critical problem for many low-income stakeholders in Tanzania. Because of its enormous consumption of energy, water, and raw materials, the construction industry has been proved for direct accountability to environmental challenges, including climatic change, resource reduction, and environmental degradation, hence considered to be the main waste contributor [54]. However, to create a friendly environment with an efficient resource (energy and materials), the global construction industry needs to promote sustainable construction continuously. Conversely, the most ranked strategies should be given priority by SMC during strategy implementation to attain improved performance. Resource availability, allocation, utilization, and management need to be advocated. The prioritized strategies will provide a direction to SMC to appropriately, efficiently, and effectively allocate, utilize, and manage resource within the acceptable ethics to attain the intended performance goal. However, government policy should be enforced for quick and easy implementation of the strategy to accelerate SMC growth.

3.5. Strategy Prioritization. Strategy prioritization has been noted of essential to realize an improved performance in LDCs' construction market. Factor analysis was considered the best optional method to facilitate the generation of a small set of a rotated component matrix. Factor analysis is a statistical method applied to describe the variability among observed variables that helps to recognize a relatively lower number of uncorrelated variables called factors. A factor is a set of observed variables that have similar patterns of response. Principal component analysis (PCA) was conducted using SPSS 24.0 to test if the measurement variables can be reduced to a small group. PCA is a well-established statistical approach of variable reduction basing on the correlation of variables. The researcher conducted two tests, including Kaiser-Meyer-Olkin (KMO) and Bartlett's test of sphericity. As itemized, the KMO statistic varies between 0 and 1, where a value close to 1 indicates that the patterns of correlations are relatively compact and that PCA would yield distinct and reliable factors. However, the calculated KMO measure produced a value of 0.806 , and the associated Bartlett test was (2175.445) at a significance level of 0.000 . However, the calculated KMO has indicated a good fit of data adequate for factor analysis.

The six-component cluster matrix of 27 prioritized strategies with a factor loading above the recommended value was extracted from principal component analysis (PCA). After varimax rotation, the cluster matrix created a pattern of uncorrelated strategies with eigenvalues greater than one (1) accounting to $73.32 \%$ of the total variance explained (Table 9). Each of the 27 strategies belongs to only one pillar of the seven-cluster matrix. After a thorough evaluation of strategies constituting a particular cluster, each cluster was named for easy identification and interpretation. Therefore, seven clusters were, namely, design (D), procurement $(\mathrm{P})$, construction management $(\mathrm{CM})$, resource $(\mathrm{R})$, capacity building $(\mathrm{CB})$, operational $(\mathrm{O})$, and government policy $(\mathrm{G})$. In addition, the correlation between prioritized strategies was computed using the Pearson coefficient at a confidence level of 95\% $(\alpha=0.05)$. The findings (Table 10) suggest that four (4) design, three (3) procurement, four (4) construction management, five (5) resources, three (3) capacity building; four (4) operational; and four (4) government policy strategies have portrayed a positive correlation at a significant value $(p<0.01$ and $p<0.05)$. The findings suggest that the strategies are sensibly correlated and statistically significant to improve SMC's performance. Moreover, the confirmatory factor analysis (CFA) was performed to test if the theoretical model of relationships among constructs is consistent with a given set of data. It, therefore, assists the researchers to either confirm or reject a preconceived theory.

Two tests were performed involving convergent and discriminant validity which tested the extent of closeness and divergence between the given latent variables. To determine the convergent validity, the average variance extracted (AVE) and the composite reliability (CR) were computed using SPSS-AMOS.

As suggested by Prudon [55], it is observed that all tested AVE values fall within the recommended value of equal or higher value than 0.5 and CR values fall within the acceptable value of equal or higher value than 0.7 (Table 6). 
TABLE 9: Rotated component matrix of prioritized strategies.

\begin{tabular}{|c|c|c|c|c|c|c|c|c|}
\hline \multirow{2}{*}{ Code } & \multirow{2}{*}{ Strategies } & \multicolumn{7}{|c|}{ Component clusters } \\
\hline & & 1 & 2 & 3 & 4 & 5 & 6 & 7 \\
\hline & A: resources $(\mathrm{R})$ & & & & & & & \\
\hline OS1 & Establish and provide support to firms to access finance and loan & & & & & & & 0.814 \\
\hline OS4 & Invest in technology and establish technology transfer centre & & & & & & & 0.838 \\
\hline OS19 & Employ competent and technical employees & & & & & & & 0.861 \\
\hline OS5 & Optimization of local quality construction materials & & & & & & & 0.763 \\
\hline OS18 & $\begin{array}{c}\text { Establish construction equipment centre } \\
\text { B: capability building (CB) }\end{array}$ & & & & & & & 0.891 \\
\hline OS6 & Facilitate training for capacity building & & 0.705 & & & & & \\
\hline OS10 & Enhance networking to share experience & & 0.669 & & & & & \\
\hline OS7 & $\begin{array}{l}\text { Adopt joint venture and partnership with an overseas firm } \\
\qquad \text { C: operational }(\mathrm{O})\end{array}$ & & 0.886 & & & & & \\
\hline OS11 & Ensure resource availability, allocation, and utilization & & & 0.631 & & & & \\
\hline OS3 & Adhere to low firm operational cost & & & 0.787 & & & & \\
\hline OS13 & Ensure employee's right working environment & & & 0.789 & & & & \\
\hline OS2 & $\begin{array}{l}\text { Adopt a low bidding price strategy } \\
\text { D: government policy }(\mathrm{G})\end{array}$ & & & 0.771 & & & & \\
\hline OS17 & Policy on compulsory joint venture & & & & & & 0.696 & \\
\hline OS12 & Training certification by government & & & & & & 0.595 & \\
\hline OS9 & Implement tax reduction policy of imported equipment and materials & & & & & & 0.741 & \\
\hline OS8 & $\begin{array}{c}\text { Policy formulation of construction bank establishment } \\
\text { E: design (D) }\end{array}$ & & & & & & 0.740 & \\
\hline SCP1 & Employ a competent design expert & & & & 0.800 & & & \\
\hline SCP21 & Gather a complete design requirement for client and stakeholders & & & & 0.681 & & & \\
\hline SCP4 & Allocate a balanced design resources & & & & 0.723 & & & \\
\hline SCP2 & $\begin{array}{c}\text { Integrate design team with another related department } \\
\text { F: procurement }(\mathrm{P})\end{array}$ & & & & 0.729 & & & \\
\hline SCP15 & Reviewing the conflicting procurement policy, laws, and regulations & & & & & 0.791 & & \\
\hline SCP11 & Adopt an electronic-tendering system to reduce a bidding cycle time & & & & & 0.698 & & \\
\hline SCP7 & $\begin{array}{c}\text { Adherence to procurement ethics and code of conduct } \\
\text { G: construction management }(\mathrm{CM})\end{array}$ & & & & & 0.717 & & \\
\hline SCP10 & Resource (finance, schedule, material, and equipment) management & 0.903 & & & & & & \\
\hline SCP18 & Quality assurance (standard and specification) & 0.798 & & & & & & \\
\hline SCP12 & Select a competent, experienced, and accessible contractors & 0.789 & & & & & & \\
\hline SCP16 & Adoption of modern construction technique & 0.762 & & & & & & \\
\hline & Note: (1) initial eigenvalues & 6.887 & 3.328 & 1.422 & 1.316 & 1.184 & 1.017 & 1.279 \\
\hline & (2) Percentage of variance (\%) & 31.306 & 15.129 & 6.464 & 5.984 & 5.383 & 4.625 & 4.431 \\
\hline & (3) Cumulative percentage of initial eigenvalues & 31.306 & 46.435 & 52.899 & 58.883 & 64.265 & 68.890 & 73.321 \\
\hline
\end{tabular}

The result justifies that the latent variables have a convergent validity and the constructs are related to each other measuring a particular consult. Furthermore, the discriminant validity involved measurement of the degree of differences between the given overlapping variables. The result (Table 11) designates that factor loading as an indicator values load strongly or higher on their respective diagonal constructs than other constructs with a cutoff value of or above 0.70 compared to the correlation values of the latent variables. However, Hair et al. supported that the diagonal is the square root of the AVE of the latent variables and indicates the highest in any column or row than the correlation within other latent variables. The findings suggest the presence of discriminant validity that gives strength to the allocation for each item on the specified latent construct.
3.5.1. Discussion. As shown in Table 9, seven clusters have been developed resulted from the list of highly prioritized strategies identified to accelerate performance improvement of SMC.

(1) Resources (R) Strategy. The construction industry is believed to consume much of the resources deemed necessary for enhancing improved performance. Resources include materials, equipment, finance, time, and human resources, to mention a few. Most overwhelmingly, construction projects facing SMC in LDC are associated with failure to mobilize resources. To accomplish the project within the predetermined schedule and cost, and at reasonable quality, resources need to be effectively and efficiently planned, procured, allocated, utilized, and managed. Thus, having a good flow of resources at the site is one of the essential strategies to attain improved performance. It is proposed that 


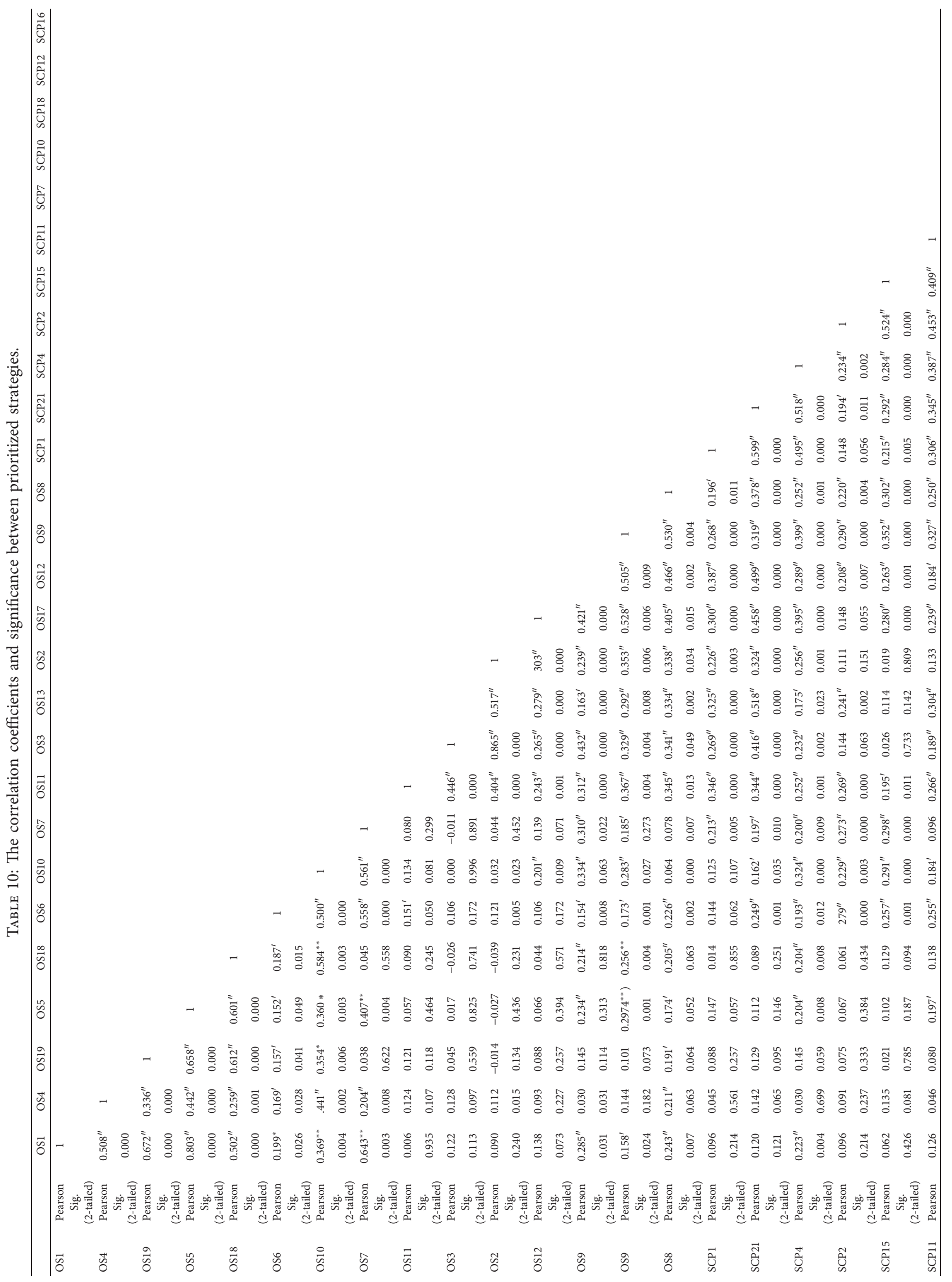




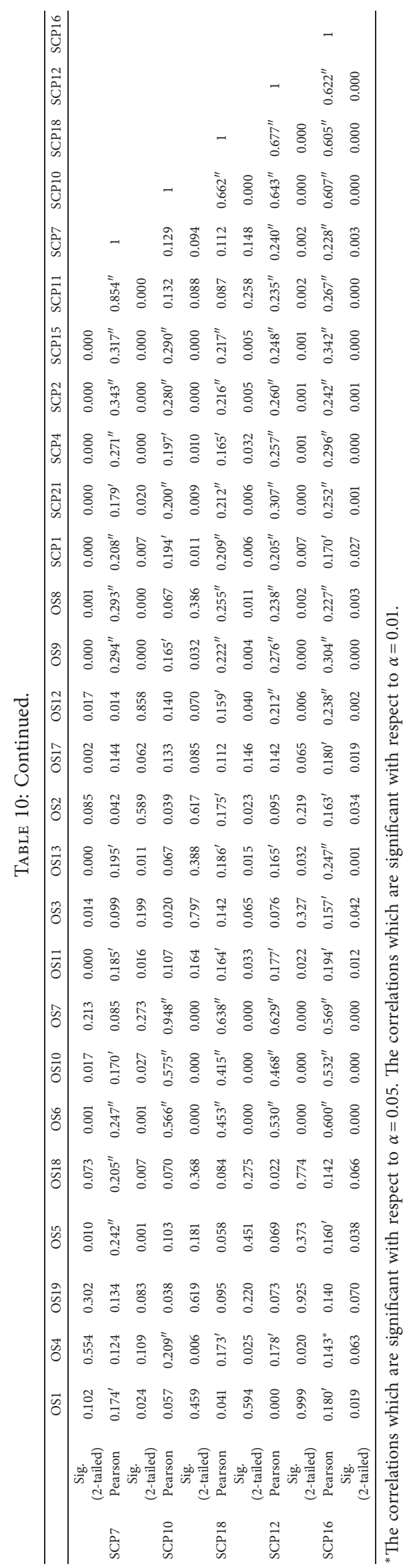


TABLE 11: Discriminant validity test result.

\begin{tabular}{lccccccc}
\hline & RE & CB & GP & OP & DE & PR & CM \\
\hline RE & $\mathbf{0 . 8 0 8}$ & & & & & & \\
CB & 0.526 & $\mathbf{0 . 8 1 3}$ & & & & & \\
GP & 0.691 & 0.519 & $\mathbf{0 . 8 1 5}$ & & & & \\
OP & 0.512 & 0.647 & 0.733 & $\mathbf{0 . 8 0 5}$ & & & \\
DE & 0.631 & 0.491 & 0.619 & 0.611 & $\mathbf{0 . 7 6 5}$ & & \\
PR & 0.588 & 0.588 & 0.621 & 0.569 & 0.517 & $\mathbf{0 . 9 6 2}$ & \\
CM & 0.483 & 0.591 & 0.591 & 0.627 & 0.497 & 0.661 & $\mathbf{0 7 7 8}$ \\
\hline
\end{tabular}

a model and system should be established for the efficient use and management of resources in the construction project.

(2) Capacity-Building Strategy. Capacity building can be associated with capacity development that involves the empowerment of employees through resource provision, a joint venture for knowledge, and information sharing to attain a sustainable transformational change within a firm. Besides, capacity-building strategies include investing in technology, provision of strong incentives to motivate employees, and specialized training to strengthen individual skills [56]. Thus, SMC needs to capacitate local firms to attain improved performance.

(3) Operational Strategy. Most construction firm operation strategy(s) are less clearly and poorly defined. They also receive less attention in practice than those of construction core and process management [57]. A precise operational strategy including ensuring resource availability, allocation, and utilization, adherence to low firm operational cost, providing employee's better working environment, and adoption of low bidding price can define the firm operations to support a business strategy. Moreover, they assist in lowering the substantial operational cost of the firm, which led to increasing profit on construction projects. Therefore, SMC is emphasized and encouraged to undertake a selfassessment to identify and define the operational strategy in line with processes set to attain an improved performance to accomplish the projects within time, cost, and value for money.

(4) Government Policy Strategy. The government is one of the top most contributors to the construction industry as it acts as a client, financier, and regulator of the industry. It plans, prepares, sets, and enforces a policy to improve the performance of the sector. Government policy is one of the crucial strategies for SMC to attain improved performance. The government requires to exert its power and create a conducive enabling environment through its regulation, policies, strategies, and institutional and other supports. The study proposes to governments to formulate policies on the establishment of construction banks, to enforce policy on a compulsory joint venture between local and foreign firms on public projects, to certify training, and to implement tax reduction policy for imported equipment and materials. However, the government, as a major client to CI, is advised to create and enforce a stable and tightly policies that will influence the construction firm's growth.
(5) Design Strategy. Since the construction involves a modern and complicated design process, it necessitates the establishment of design strategies. The strategies encompass the employment of a competent design expert, availability of complete design requirement deliverables for client and stakeholders, allocation of balanced design resources, alliance, and partnership among experts as well as an integrated design team with related firm section. This study advises that, for SMC to reduce or avoid reworks and easy and quick design control and attain improved design performance, an appropriate design management system approach should be established.

(6) Procurement Strategy. Due to intense competition among contractors, procurement strategy is believed to be the best technique to enable firms to win more tenders. However, the procurement process is a difficult, demanding, and challenging task from a management perspective in the construction industry. Procurement involves sourcing, negotiation, and strategically selection of goods and services for an organization or firm consumption and use. A reliable procurement system dictates the way the construction projects are executed, as its procedures always affect the project delivery system. However, procurement strategies, including reviewing the conflicting procurement policy and regulations, adoption of an electronic-procurement system to reduce a bidding cycle time, and adherence to procurement ethics and code of conduct cannot be ignored are influential to SMCs to attain improved performance. However, the selection of a suitable procurement method and the evaluation criteria to get an appropriate supplier for a particular construction project have remained of much concern since it assists in organizing the resources effectively and portrays the competence of the firm.

(7) Construction Management Strategy. Construction management (CM) entails the overall organization (planning, coordinating, and controlling) of the project resource (finance, schedule, material, and equipment) from inception to completion in order to attain a functionary and a sustainable project which satisfy the client's or user's requirements. A proper adherence and application of CM knowledge provide a competitive advantage to the construction firm, which results in successful project delivery. It is CM, which can help to attain the project success drivers. Thus, SMC needs to critically apply the CM strategy which involves but not limited to quality assurance (standard and specification), use of quality materials, adoption of modern construction techniques and resources mobilization, planning, allocation and utilization of time, cost, quality, safety control and environmental management, and sustainability.

3.6. Structural Equation Modelling. Structural equation modelling (SEM) representing the prioritized strategies was drawn using SPSS-AMOS (Figure 4). A model can be defined as a statistical statement that denotes a relationship between variables. SEM consists of a statistical structural model that represents a relationship between latent variables of the 


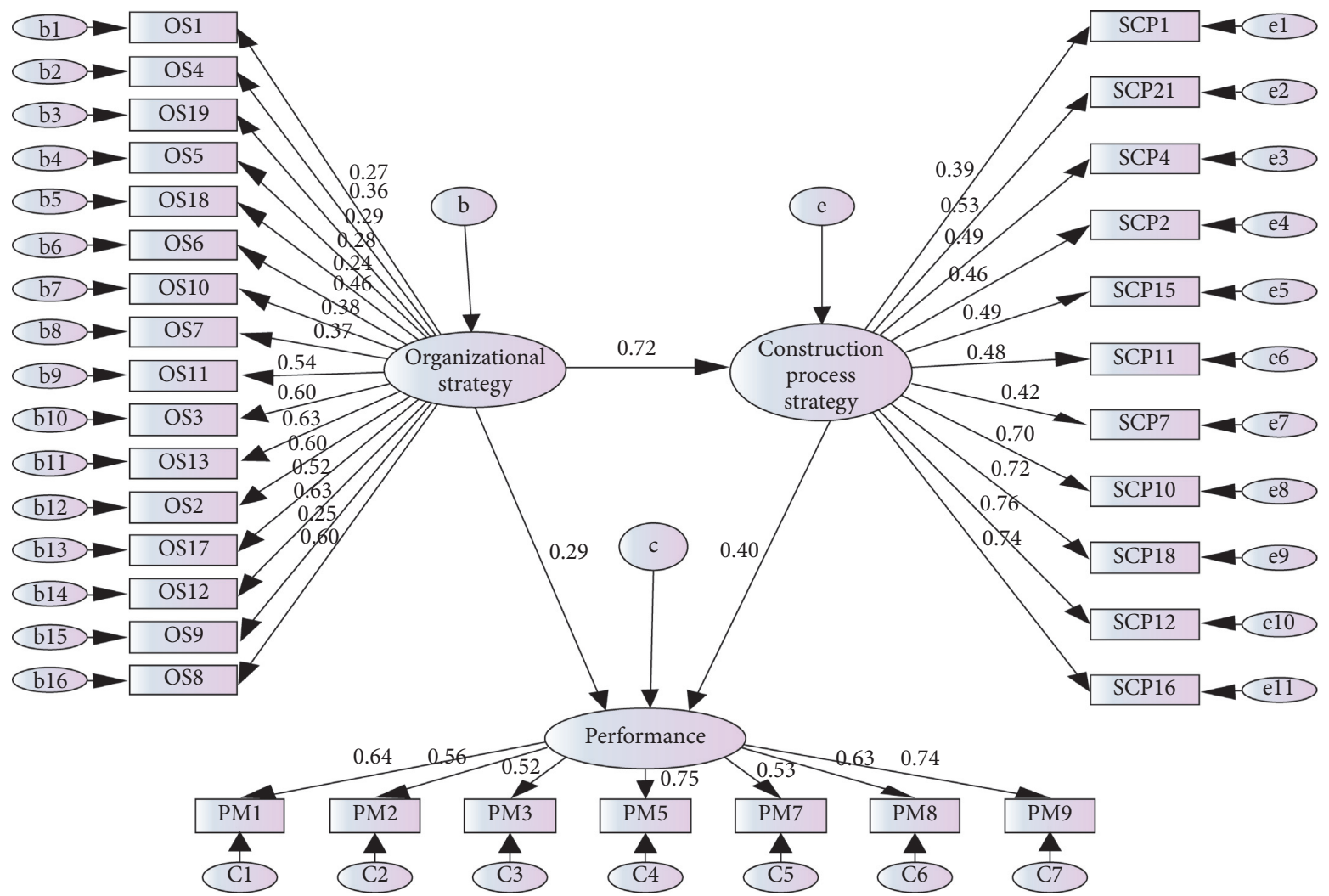

FIGURE 4: A structural modelling diagram; source: researchers.

TABle 12: Model fit indices (MFIs).

\begin{tabular}{|c|c|c|c|}
\hline $\mathrm{S} / \mathrm{N}$ & Model fit indices (MFIs) & Acceptable MI limit & Computed result indices (CRIs) \\
\hline 1 & $\begin{array}{c}\text { Absolute model fit } \\
\text { Chi-square indices }\left(\chi^{2}\right) \\
\text { Degree of freedom }(\mathrm{df})\end{array}$ & & $\begin{array}{c}2477.3 \\
535\end{array}$ \\
\hline 2 & $\begin{array}{c}\text { Parsimonious fit } \\
\text { Minimum discrepancy }\left(\chi^{2} / \mathrm{df}\right) \\
\text { RMSEA }\end{array}$ & $\begin{array}{l}<5 \text { better } \\
<0.07 \text { good }\end{array}$ & $\begin{array}{l}4.63 \\
0.77\end{array}$ \\
\hline 3 & $\begin{array}{c}\text { Incremental fit } \\
\text { Tucker-Lewis Index (TLI) } \\
\text { Comparative Fit Index (CFI) } \\
\text { Adjusted Goodness of Fit Index (AGFI) }\end{array}$ & $\begin{array}{l}>0.8 \text { good } \\
>0.9 \text { better } \\
>0.9 \text { better }\end{array}$ & $\begin{array}{l}0.823 \\
0.912 \\
0.987\end{array}$ \\
\hline
\end{tabular}

intended feature and the measurement models that characterize the correlation between latent variables and their manifest indicators. In this study, the structural model consists of three measurement models with three latent variables, namely, organizational strategy, construction core process strategy, and performance. SEM provides a data comparison that produces a statistical-model fit that assists in evaluating the relationship between the model and data. However, if the model fit falls within the recommended model fit indices (Table 12), the relationships between latent and observed variables are considered being supported by the data.

Adequate sample size is required to use SEM. Since this study applied the maximum likelihood method (MLM) to estimate the parameter and compute the model fit, referring the proposed alternative of following the lower bound of 200 sample size validated the adoption of SEM to indicate the correlation between the prioritized strategies. The model generated in this study (Figure 4) has reported a significant relationship (72\%) between two measurement models (organizational strategies and construction core process strategies). However, construction core process strategies have shown $40 \%$ and $29 \%$ of corporate strategy contribution to attaining an improved performance to SMC.

The effectiveness of the model, to a great extent, depends on the measurement of the fitness of the model. The SPSSAMOS output, which has provided the data comparison and the computed estimates of model indices (MIs) from SEM using maximum likelihood estimate method, has produced an acceptable model fit index (Table 12). Thus, the result has 
shown that $\chi 2=2477.3$, minimum discrepancy of 4.63 , $\mathrm{TLI}=0.823, \mathrm{CFI}=0.912, \mathrm{AGFI}=0.987$, and $\mathrm{RMSEA}=0.77$. The findings present the significant relationship between the prioritized organizational strategies and construction core process strategies to facilitate performance improvement of SMC.

\section{Conclusion}

To attain an improved performance of a construction firm is currently a hot topic in LDC since many factors constitute it. However, because of resource scarcity, it is quite hard to satisfy all the required elements. Scores of the literature have revealed that inadequate performance of SMC in LDCs has a huge disadvantage in terms of time, cost, quality, safety, environment, and hence little or no firm growth. Thus, to realize a drastic change on performance, SMC should invest on resources and opt for only potential organizational and $\mathrm{CM}$ process as value activities and willingly to effectively prioritize the strategies through re-engineering process to guarantee the satisfaction of the client and other stakeholders as an achievement of the firm's vision.

The finding from the study can be drawn that, due to the changes in the construction process driven by the change or shift in technology and environment, they have demanded the local firms to adopt the re-engineering process, which necessitates the need for a drastic change on core construction process and strategies. Moreover, local firms need to adapt the technology to a straightforward construction process undertaking to attain improved performance. Besides, the study has argued for local firms to explore and encourage the collaboration and communication approach between local firms and foreign firms in the construction process. This technique intends to improve resource availability and utilization, experience, design technique, construction operations, and management skills, buildability, transparency, and equitable procurement and life cycle quality assurance to attain required flexibility throughout the entire construction process phases. However, the government policy was noted to facilitate capacity building in almost all aspects including but not limited to better construction environment, quality resource availability at a reasonable cost, and enforcement of laws and regulation on joint venture aiming to attain a quality construction with value for money. Thus, the identified twenty-seven (27) strategies in this study clustered into resources, capacity building, operational, government policy, design, procurement, and construction management have found to have a positive significance to improve the firm's performance.

This study has addressed a model of strategies that can assist stakeholders and construction industry policymakers in identifying the prioritized strategies required to improve the performance. In the course of developing the model under the given specific context of LDC, it was obligatory to recognize the SMC's weakness, performance measurement indicators, and organizational and construction core process strategies, which are main features where the model dependability relies on. However, awareness of BPR, the presence of the qualified team, resources, and comprehensive government policy were noted of paramount importance for the SMC's dramatic changes. This study has reflected the LDC environment. However, it is to be accredited that the prioritized strategies reflecting SMC can radically change due to a dynamic and turbulent construction market environment changes.

\section{Study Limitations and Direction for Future Research}

This study was limited to develop a model of prioritized strategies for small and medium firm's performance improvement in Tanzania as one of the less-developed countries. The study adopted a business re-engineering process philosophy to study the prevailing SMC's environment, which helped to identify the performance weakness, the firm's attributes, and potential strategies of SMC. The study findings can be generalized only to construction firms with similar construction characteristic environments as of LDC. Future research is recommended to study the role of information technology (IT) in facilitating the implementation of BPR for SMC to attain an improved and adequate performance.

\section{Data Availability}

The data collected and used for analysis will be available from the corresponding author upon request.

\section{Conflicts of Interest}

The authors declare that there are no conflicts of interest regarding publication of the article.

\section{Acknowledgments}

The authors are grateful to acknowledge the Chongqing University in China for financing this study under the Fundamental Research Fund for the Central Universities.

\section{References}

[1] S. Degu, "Assessing the effect of business process reengineering on organizational performance: a case study of Bureau of finance and economic development (BoFED), OROMIA regional state, Ethiopia," International Refereed Research Journal, vol. 4, no. 1, pp. 115-123, 2013.

[2] Rameezdeen, Image of The Construction Industry, Department of Building Economics, University of Moratuwa, Moratuwa, Sri Lanka, 2007.

[3] G. Ofori, New Perspectives on Construction in Developing Countries, Spon Press, Abingdon, UK, 2001.

[4] G. Ofori, "Challenges for construction industries in developing countries," in Proceedings of the Second International Conference of the CIB TG 29, pp. 1-11, Gaborone, Botswana, November 2000.

[5] G. Kululanga, "Capacity building of construction industries in Sub-Saharan developing countries a case for Malawi," Engineering, Construction and Architectural Management, vol. 19, no. 1, pp. 86-100, 2012. 
[6] K. Ye, L. Shen, and J. Zuo, "Utilizing the linkage between domestic demand and the ability to export to achieve sustainable growth of construction industry in developing countries," Habitat International, vol. 38, pp. 135-142, 2013.

[7] R. Tekka and K. Ye, "The paradox of small and medium construction firms sustainability in less developed countries," in Proceedings of the 24th International Symposium on Advancement of Construction Management and Real Estate:29th November-2nd December 2019, Chongqing, China, 2019.

[8] B. Muhegi, "Status of implementation of recommendations from the CRB annual workshops 2002," in Proceedings of the Annual Consultative Meetings, Proceedings CRB's Five Year Corporate Plan; Goals and Strategies, Da es Salaam, Tanzania, June 2003.

[9] S. Christopher, "The dynamics of fit and the fit of dynamics: aligning IT in a dynamic organization," in Proceedings of the International Conference on Information Systems (ICIS), Vancouver, British Columbia, Canada, December 1994.

[10] J. Bauchet and J. Morduch, "Is micro too small? Microcredit vs. SME finance," World Development, vol. 43, pp. 288-297, 2013.

[11] M. Yahya and P. Mutarubukwa, "Capacity of Tanzanian micro, small and medium enterprises (Mmses) in tapping the business opportunities in the east african community," Business Education Journal, vol. 1, no. 1, pp. 1-20, 2015.

[12] I. C. Anugwo, "Potentiality of the South African construction SMME contractors globalising within and beyond the SADC construction markets," Journal of Construction Business and Management, vol. 2, no. 1, pp. 41-49, 2018.

[13] B. Rijkers, M. Söderbom, and J. L. Loening, “A rural-urban comparison of manufacturing enterprise performance in Ethiopia," World Development, vol. 38, no. 9, pp. 1278-1296, 2010.

[14] M. Sexton and P. Barrett, "Appropriate innovation in small construction firms," Construction Management and Economics, vol. 21, no. 6, pp. 623-633, 2003.

[15] URT, "Micro small and medium enterprises in Tanzania: national baseline survey report:ministry of trade and industry," Financial Sector Deepening Trust (FSDT), Dar es Salaam, Tanzania, 2012.

[16] NBS, "National baseline survey report for micro, small, and medium enterprises in Tanzania," Financial Sector Deepening Trust (FSDT), Dar es Salaam, Tanzania, 2012.

[17] J. Bughin, The Impact of Internet Technologies: Search, McKinsey \& Company, New York, NY, USA, 2011.

[18] I. Kazungu, "Improving livelihoods through micro and small agribusiness enterprises: analysis of contributions, prospects and challenges of nursery gardens in arusha Tanzania," International Journal of Business Management, vol. 6, no. 9, 2014.

[19] J. N. Nkwabi and L. B. Mboya, "A review of factors affecting the growth of small and medium enterprises (SMEs) in Tanzania," European Journal of Business and Management, vol. 11, no. 33, pp. 1-8, 2019.

[20] A. Faridi and S. El-Sayegh, "Significant factors causing delay in the UAE construction industry," Construction Management and Economics, vol. 24, pp. 1167-1176, 2006.

[21] O. Taouab and Z. Issor, "Firm performance: definition and measurement models," European Scientific Journal, vol. 15, no. 1, 2019.

[22] G. Manville, "Implementing a balanced scorecard framework in a not for profit SME," International Journal of Productivity and Performance Management, vol. 56, no. 2, pp. 162-169, 2007.
[23] A. Mba and E. Cletus, "Issues, challenges and prospects of small and medium scale enterprises (SMEs) in port-Harcourt city, Nigeria," European Journal of Sustainable Development, vol. 3, no. 1, pp. 101-114, 2014.

[24] L. Weisheng, "Critical success factors for competitiveness of contractors: China study.China," Journal of Construction Engineering and Management, vol. 134, no. 12, pp. 972-982, 2008.

[25] O. Furrer, "The structure and evolution of the strategic management field: a content analysis of 26 years of strategic management research," International Journal of Management Reviews, vol. 10, no. 1, pp. 1-23, 2008.

[26] E. Penrose, The Theory of Growth of The Firm, Blackwell, Oxford, UK, 1959.

[27] Y. Zhang, "Organizational structure, slack resources and sustainable corporate socially responsible performance," Corporate Social Responsibility and Environmental Management, vol. 25, pp. 1099-1107, 2018.

[28] R. Recardo, "Let There Be Light: building strategic planning capability," Global Business and Organizational Excellence, vol. 35, pp. 38-49, 2016.

[29] K. Odusami, "Perception of professionals concerning important skills of effective project leader," Journal of Management in Engineering, vol. 18, no. 2, pp. 61-67, 2002.

[30] G. Wang and J. Yang, "Business development strategy and Australian construction industry," International Journal for Construction Marketing, vol. 2, no. 1, 2011.

[31] G. Abd, "Critical internal and external factors that affect firms strategic planning," International Research Journal of Finance and Economics, vol. 51, pp. 50-58, 2010.

[32] C. Anca, "The role of strategy in the new organizational context," Holistic Marketing Management Journal, vol. 2, no. 3, pp. 31-55, 2012.

[33] A. Shaukat, Y. Qiu, G. Trojanowski et al., "Corporate social responsibility strategy, and corporate environmental and social performance," Journal of Business Ethics, vol. 135, no. 3, pp. 569-585, 2016.

[34] P. M. Clarkson, "Does it really pay to be green? determinants and consequences of proactive environmental strategies," Journal of Accounting and Public Policy, vol. 30, pp. 122-144, 2011.

[35] A. Sidwell, Reengineering the Construction Delivery Process, Report and Case Studies, Construction Industry Institute Australia, Australia, 2002, http://www.ciia.qut.com.

[36] M. Hammer and J. Champy, Re-engineering the Corporation, Nicholas Brealy, London, UK, 1993.

[37] S. Ahmed, "Integrating DMAIC approach of Lean Six Sigma and theory of constraints toward quality improvement in healthcare," Reviews on Environmental Health, vol. 34, no. 4, pp. 427-434, 2019.

[38] H. Taherdoost, "Determining sample size:how to calculate survey sample size," International Journal of Economics and Management Systems, vol. 2, pp. 237-239, 2017.

[39] N. Nguli, Re: How to score a likert Scale?, https://www. researchgate.net/post/How_to_score_a_likert_Scale/ 59efe557eeae39563907ec80/citation/download, 2017.

[40] J. A. Gliem and R. R. Gliem, "Calculating, interpreting, and reporting Cronbach's alpha reliability coefficient for likerttype scales," in Procedings of theMidwest Research-to-Practice Conference in Adult, Continuing, and Community Education, Columbus, OH, USA, 2003.

[41] K. Samaraweera, "What should be ideal KMO value for factor analysis?," 2020, https:/www.researchgate.net/post/What_ should_be_ideal_KMO_value_for_factor_analysis/5ebee $64 \mathrm{c} 5 \mathrm{f} 9 \mathrm{c}$ c675395089d4/citation/download. 
[42] M. Sibiya, "Construction projects' key performance indicators: a case of the South African construction industry," in Proceedings of the 2015 International Conference on Construction and Real Estate Management, Lulea, Sweden, August 2015.

[43] G. Ofori and S. R. Toor, "Leadership and construction industry development in developing countries," Journal of Construction in Developing Countries, vol. 17, no. 1, pp. 1-21, 2012.

[44] Y. C. Lee and S. K. Lee, "Capability, processes, and performance of knowledge management: a structural approach," Human Factors and Ergonomics in Manufacturing, vol. 17, no. 1, pp. 21-41, 2007.

[45] S. Faraj, "Strategies for small-medium scale contractor performance improvement in ASEAN competitive market," Procedia Engineering, vol. 12, pp. 387-395, 2017.

[46] ILO, "The construction industry in the twentyfirst century: its image, employment prospects and skill requirements," in Tripartite Meeting on the Construction Industry in the TwentyFirst Century: Its Image, Employment Prospects and Skill Requirements, Geneva, Switzerland, 2001.

[47] A. O. Windapo, "Skilled labour supply in the South African construction industry: The nexus between certification, quality of work output and shortages," SA Journal of Human Resource Management, vol. 14, no. 1, pp. 1-8, 2016.

[48] S. L. Berman, J. Down, and C. W. L. Hill, "Tacit knowledge as a source of competitive advantage in the National Basketball Association," Academy of Management Journal, vol. 45, pp. 13-31, 2002.

[49] P. E. Love, R. Lopez, D. J. Edwards, and Y. M. Goh, "Error begat error: design error analysis and prevention in social infrastructure projects," Accident Analysis and Prevention, vol. 48, pp. 100-110, 2012.

[50] H. Eliufoo, "Health \& safety knowledge at construction sites: modalities and characteristics," Public Health Research, vol. 9, no. 3, pp. 43-49, 2019.

[51] B. G. Hwang, M. Shan, S. Xie, and S. Chi, "Investigating residents' perceptions of green retrofit program in mature residential estates: the case of Singapore," Habitat International, vol. 63, pp. 103-112, 2017.

[52] J. Cao, A Structural Equation Model of Customers' Behavioural Intentions in the Chinese Restaurant Sector, $\mathrm{PhD}$ Thesis, Newcastle University Business School., Newcastle, Tyne, England, 2012.

[53] K. Vu, "Embracing globalization to promote industrialization: insights from the development of Singapore's petrochemicals industry," China Economic Review, vol. 48, pp. 170-185, 2017.

[54] H. Lidelöw and K. Simu, "Understanding construction contractors and their operations strategies," Procedia Economics and Finance, vol. 21, pp. 48-56, 2015.

[55] N. Aniekwu, Government Role in Developing the Construction Industry in Nigeria, https://www.researchgate.net/ publication/267026082, 2016.

[56] L. Pekuri, "Analysing the problem of procurement in construction," in Proceedings of the IGLC-22, Oslo, Norway, June 2014.

[57] O. Ilveskoski and S. Niittymaki, Construction Management: Study Book, Hameen Ammattikorkeakouulu (HAMK), Hämeenlinna, Finland, 2015. 